The published manuscript is available at EurekaSelect via http:// www.eurekaselect.com/openurl/content.php? genre $=$ article $\&$ doi $=10.2174 / 0929867325666180607094856$

$$
\text { (C) }{ }_{\text {Reserved }}^{\text {All Rights }}
$$

(C) Bentham Science Publishers 


\title{
Dual Inhibitors as a New Challenge for Cancer Multidrug Resistance Treatment
}

Tijana Stankovića ${ }^{\text {, Jelena Dinića }}{ }^{\text {, Ana Podolski-Renić }}{ }^{\text {, Loana Musso }}$, Sonja Stojković Burića Sabrina Dallavalle ${ }^{* b}$ and Milica Pešić ${ }^{* a}$

${ }^{a}$ Department of Neurobiology, Institute for Biological Research "Siniša Stankovič”, University of Belgrade, Belgrade, Serbia; ${ }^{b}$ DeFENS, Department of Food, Environmental and Nutritional Sciences, Università degli Studi di Milano, Milano, Italy

\begin{abstract}
:
Background: Dual-targeting in cancer treatment by a single drug is an unconventional approach in relation to drug combinations. The rationale for the development of dual-targeting agents is to overcome incomplete efficacy and drug resistance frequently present when applying individual targeting agents. Consequently, -a more favorable outcome of cancer treatment is expected with dual-targeting strategies. Methods: We reviewed the literature, concentrating on the association between clinically relevant and/or novel dual inhibitors with potential to modulate multidrug resistant phenotype of cancer cells, particularly the activity of P-glycoprotein. The balanced analysis of content was performed to emphasize the most important findings and optimize the structure of this review. Results: Two-hundred and forty five papers were included in the review. The introductory part was interpreted by 9 papers. Tyrosine kinase inhibitors' role in the inhibition of P-glycoprotein and chemosensitization was illustrated by 87 papers. The contribution of natural-based compounds in overcoming multidrug resistance was reviewed using 92 papers, while specific dual inhibitors acting against microtubule assembling and/or topoisomerases were described with 55 papers. Eleven papers gave an insight into a novel and less explored approach with hybrid drugs. Their influence on P-glycoprotein and multidrug resistance was also evaluated. Conclusion: These findings bring into focus rational anticancer strategies with dual-targeting agents. Most evaluated synthetic and natural drugs showed a great potential in chemosensitization. Further steps in this direction are needed for the optimization of anticancer treatment.

Keywords: targeted anticancer therapy, multidrug resistance, P-glycoprotein, tyrosine kinase inhibitors, natural-based drugs, microtubule interacting agents, topoisomerase inhibitors, hybrid compounds

*Address correspondence to Sabrina Dallavalle, DeFENS, Department of Food, Environmental and Nutritional Sciences, Università degli Studi di Milano, Via Celoria 2, 20133 Milano, Italy; Phone +39-2-50316818; FAX +39-2-50316801; E-mail: sabrina.dallavalle@unimi.it. Address correspondence to Milica Pešić, Department of Neurobiology, Institute for Biological Research "Siniša Stanković", University of Belgrade, Despota Stefana 142, 11060 Belgrade, Serbia; Phone +381-11-2078406; FAX +381-11-2761433; E-mails: camala@ibiss.bg.ac.rs; pesicmilica7@gmail.com
\end{abstract}




\section{INTRODUCTION}

New drug design in anticancer research is guided by the increasing knowledge of druggable targets. The main idea behind this approach is that modulation of a particular cancer biomarker will achieve a therapeutic benefit. Selective drugs against cancer cells should eradicate tumors more specifically, reducing side effects in normal cells. However, the inhibition of a single target often shows transient efficacy due to the development of drug resistance. Knowing that cancers are heterogeneous entities, the simultaneous intervention on multiple targets is necessary to obtain the optimal effect.

One way to achieve the simultaneous blockage of two or multiple targets is combination chemotherapy. However, two or more drugs often possess different pharmacokinetic profiles and metabolic stabilities. In addition, combination chemotherapy may produce adverse drug-drug interactions. An alternative strategy to overcome these problems is to suppress two or multiple targets with a single drug. This approach could even simplify patients' treatment. However, the risk of off-target activity is present with dual/multi-targeting agents. Therefore, integrated approaches in designing multi-targeting compounds are necessary to enable blockage of the desired oncogenic pathways $[1,2]$. However, newly designed drug with a potential to inhibit several targets should be tested against cancer multidrug resistance (MDR) because the development of MDR is one of the main issues that can arise during the course of any anticancer therapeutic strategy [3]. While MDR includes a large variety of factors and processes, the key trigger is usually the overexpression of adenosine triphosphate (ATP)-binding cassette (ABC) transporters in the cell membrane. P-glycoprotein (P-gp) is an MDR efflux pump that transports a wide range of xenobiotic compounds out of the cell implying inhibition of P-gp transport as an attractive therapeutic strategy for overcoming MDR. Numerous newly discovered P-gp inhibitors exhibited significant side-effects and haven't successfully passed clinical trials [3, 4].

P-gp shows high promiscuity with more than 300 compounds identified as its substrates. Pgp functioning depends on ATP hydrolysis. On the other side, its ATPase activity is stimulated by substrates. Although, P-gp possesses two active ATPase sites, only one ATP is hydrolyzed at a time. Recent study showed that substrate release occurs prior to ATP hydrolysis [5].

Highly flexible drug-binding pocket is perceived as an important characteristic of P-gp that enables different compounds to bind P-gp at the same time [6]. In addition, the same compound could bind several distinct sites on P-gp [7].

P-gp inhibition occurs when the transporter is overloaded by its substrate and the hydrolysis of ATP is highly stimulated, as well as when ATP-binding or ATP-hydrolysis is suppressed. Alternatively, P-gp activity could be decreased due to the inhibition of its expression [8].

Herein, we review current studies on small molecule inhibitors that act against several targets and at the same time interact with resistant phenotype in a preferable way by inhibiting P-gp activity/expression in MDR cancer cells. In addition, we discuss the challenges and the potential of dual inhibitors in cancer treatment.

The first group of dual-targeting agents in focus of this review is comprised of tyrosine kinase inhibitors (TKIs). TKIs interfere with the binding of ATP, causing direct inhibition of tyrosine kinases' catalytic activity [9] and may also inhibit the activity of ABC transporters by binding at their nucleotide binding domains.

Compounds of natural origin are the second group of evaluated dual-targeting agents. Many of them exerted significant anti-P-gp activity. This feature qualified natural-based compounds as promising drug candidates for MDR treatment.

Two important targets in anticancer research are microtubules and topoisomerases. Compounds designed to target microtubules and other targets within cancer cell, compounds that 
target both topoisomerases I and II, and dual inhibitors of microtubules and topoisomerases were also evaluated in this review.

In addition, special attention is given to the hybrid compounds comprised of different scaffolds and moieties with stronger anticancer and anti-P-gp potential than parental compounds.

Although, this is not a final list of compounds that act against dual/multi-targets, the aim of this review is to introduce some major classes of synthetic, natural and hybrid compounds with such properties in the context of MDR, particularly P-gp inhibition.

\section{TYROSINE KINASE INHIBITORS}

Tyrosine kinase inhibitors (TKIs) are small hydrophobic molecules that easily penetrate into cells and target both membrane bound and cytoplasmatic kinases. Most TKIs are multikinase inhibitors that simultaneously target several kinases, therefore affecting multiple cellular processes deregulated in cancers. Even though they are very potent anticancer drugs beneficial in the treatment of a substantial number of cancer patients, the development of acquired resistance significantly limits the efficiency of TKI therapies. One of the mechanisms that contribute to the resistance to TKIs is overexpression ABC transporters, particularly $\mathrm{P}$-gp (coded by ABCB1/MDR1 gene) [10]. Most TKIs are substrates for ABC transporters which by pumping inhibitors out of the cells limit their oral bioavailability, brain penetration, and finally, intracellular level [11]. However, depending on the applied concentrations of TKIs, their interaction with $\mathrm{ABC}$ pumps can be rather complex. Since TKIs interfere with the ATP-binding, it is reasonable to expect that TKIs may also inhibit the activity of $\mathrm{ABC}$ transporters. For most TKIs such inhibitory function against $\mathrm{ABC}$ transporters is reported at higher concentrations [12]. Unlike other $\mathrm{ABC}$ transporters substrates, that at higher concentration could also inhibit these pumps, inhibitory TKI concentrations are still clinically achievable and at the same time tolerable. This is of particular significance for TKI application in combined treatments with ABC transporters substrates in order to re-sensitize resistant tumor cells to therapy [11, 13]. Importantly, it was demonstrated that some TKIs act solely as ABC transporters inhibitors either suppressing their activity or expression [12]. To elucidate whether TKIs (as well as other anticancer agents) inhibit P-gp merely by overloading the transporter or as true P-gp inhibitors, MDR models comprised of pairs of sensitive/resistant cell lines have to be employed [14]. No significant discrepancy between $\mathrm{IC}_{50}$ values obtained in sensitive and corresponding resistant cells with P-gp overexpression indicate that particular anticancer agent is not a substrate for Pgp. If such compound is able to inhibit P-gp activity, it should be considered as a true P-gp inhibitor.

In this review, we discuss the main aspects of the inhibitory interaction of clinically relevant TKIs with P-gp, as the most important representative of ABC transporters, and their modulatory effect on drug resistance. The information regarding TKIs targets and anti-P-gp functions is summarized in Table 1.

Table 1. Tyrosine kinase inhibitors with multi-targeting and anti-P-gp potential

\begin{tabular}{|c|c|c|c|c|c|c|}
\hline \multirow[t]{2}{*}{ TKI } & \multirow[t]{2}{*}{$\begin{array}{l}\text { Alternate } \\
\text { name(s) }\end{array}$} & \multirow[t]{2}{*}{$\begin{array}{l}\text { Target } \\
\text { kinases }\end{array}$} & \multicolumn{2}{|r|}{ Effect on P-gp } & \multicolumn{2}{|c|}{ Chemosensitization } \\
\hline & & & $\begin{array}{l}\text { Functional } \\
\text { inhibition }\end{array}$ & $\begin{array}{c}\begin{array}{c}\text { Downregulation } \\
\text { of expression } \\
\text { (mRNA }\end{array} \\
\text { and/or protein) } \\
\end{array}$ & $\begin{array}{c}\text { In vitro } \\
\text { (cancer cell types) }\end{array}$ & $\begin{array}{c}\text { In vivo } \\
\text { (cancer types) }\end{array}$ \\
\hline \multicolumn{7}{|c|}{ Bcr-Abl inhibitors } \\
\hline Imatinib & $\begin{array}{l}\text { STI-571, } \\
\text { Gleevec } \AA, \\
\text { Glivec } \AA\end{array}$ & $\begin{array}{l}\text { Bcr-Abl, } \\
\text { PDGFR, c- } \\
\text { KIT }\end{array}$ & + & + & $\begin{array}{l}\text { myelogenous leukemia } \\
\text { (K562/A02)[17], } \\
\text { embryonic kidney cells (HEK- }\end{array}$ & $\mathrm{n} / \mathrm{a}$ \\
\hline
\end{tabular}




\begin{tabular}{|c|c|c|c|c|c|c|}
\hline & & & & & $\begin{array}{c}293 \text { ABCB1)[18], epidermoid } \\
\text { carcinoma (KB-G2)[19], } \\
\text { amelanotic melanoma } \\
\text { (35s/M14), breast carcinoma } \\
\text { (BT-549)[20] }\end{array}$ & \\
\hline Nilotinib & $\begin{array}{l}\text { AMN107, } \\
\text { Tasigna }{ }^{\circledR}\end{array}$ & $\begin{array}{l}\text { Bcr-Abl, } \\
\text { PDGFR, c- } \\
\text { KIT }\end{array}$ & + & + & $\begin{array}{l}\text { epidermoid carcinoma (KB-C2, } \\
\text { KB-V1)[26,29], synovial } \\
\text { sarcoma (SW982), } \\
\text { leiomyosarcoma (SK-UT-1)[25], } \\
\text { leukemia (CD34+CD38- stem), } \\
\text { epidermoid carcinoma } \\
\text { (KBv200), colorectal } \\
\text { adenocarcinoma (S1-M1- } \\
\text { 80)[27], osteosarcoma } \\
\text { (MG63/DOX)[28] }\end{array}$ & $\begin{array}{c}\text { osteosarcoma MG63/DOX } \\
\text { xenografts in athymic } \\
\text { BALB/c-nude mice[28]; } \\
\text { epidermoid carcinoma KB- } \\
\text { C2, NSCLC H460/MX-20, } \\
\text { embryonic kidney } \\
\text { HEK/MRP7 xenografts in } \\
\text { athymic NCR (nu/nu) nude } \\
\text { mice[29] }\end{array}$ \\
\hline Dasatinib & $\begin{array}{l}\text { BMS-354825, } \\
\text { Sprycel }{ }^{\circledR}\end{array}$ & $\begin{array}{l}\text { Bcr-Abl, } \\
\text { c-Src, Lck, } \\
\text { Fyn, and } \\
\text { Yes }\end{array}$ & + & + & $\begin{array}{c}\text { breast carcinoma (MCF- } \\
\text { 7/ADR)[30], myeloma, } \\
\text { (RPMI8226/ADR, } \\
\text { RPMI8226/VCR, } \\
\text { RPMI8226/DEX, RPMI8226/L- } \\
\text { PAM)[32] }\end{array}$ & $\mathrm{n} / \mathrm{a}$ \\
\hline Bosutinib & $\begin{array}{l}\text { SKI-606, } \\
\text { Bosulif® }\end{array}$ & $\begin{array}{l}\text { Bcr-Abl, } \\
\text { c-Src, }\end{array}$ & + & - & $\mathrm{n} / \mathrm{a}$ & $\mathrm{n} / \mathrm{a}$ \\
\hline Ponatinib & $\begin{array}{l}\text { AP24534, } \\
\text { Iclusig }{ }^{\circledR}\end{array}$ & $\begin{array}{l}\text { Bcr/Abl, } \\
\text { FLT3,FGFR, } \\
\text { VEGFR, } \\
\text { Tie2 }\end{array}$ & + & + & $\begin{array}{c}\text { breast carcinoma (MCF- } \\
\text { 7/AdrVP), promyelocytic } \\
\text { leukemia (HL-60/VCR), } \\
\text { myeloma (RPMI8226/MR20, } \\
\text { 8226/Dox6)[33] }\end{array}$ & $\mathrm{n} / \mathrm{a}$ \\
\hline \multicolumn{7}{|l|}{ EGFR Inhibitors } \\
\hline Erlotinib & $\begin{array}{l}\text { OSI-774, } \\
\text { Tarceva@ }\end{array}$ & EGFR, Jak & + & + & $\begin{array}{l}\text { epidermoid carcinoma (KB- } \\
\text { C2)[41], myelogenous leukemia } \\
\text { (KG-1)[42], myelogenous } \\
\text { leukemia (K562/MDR)[43] }\end{array}$ & $\mathrm{n} / \mathrm{a}$ \\
\hline Afatinib & 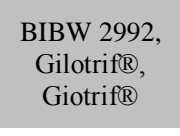 & $\begin{array}{l}\text { EGFR, } \\
\text { HER2, } \\
\text { HER4 }\end{array}$ & + & + & $\begin{array}{c}\text { ovarian carcinoma (A2780/T, } \\
\text { SKOV3-DDP)[45], NSCLC } \\
\text { (A549T)[46] }\end{array}$ & $\begin{array}{c}\text { ovarian carcinoma A2780/T } \\
\text { xenografts in athymic } \\
\text { (BALB/c-nu/nu) nude } \\
\text { mice[45] }\end{array}$ \\
\hline Neratinib & $\begin{array}{l}\text { HKI-272, } \\
\text { Nerlynx }^{\text {TM }}\end{array}$ & $\begin{array}{l}\text { HER-2, } \\
\text { EGFR }\end{array}$ & + & - & $\begin{array}{l}\text { epidermoid carcinoma } \\
\text { (KBv200), breast carcinoma } \\
\text { (MCF-7/ADR)[49] }\end{array}$ & $\begin{array}{c}\text { epidermoid carcinoma } \\
\text { KBv200 xenografts in } \\
\text { athymic (BALB/c-nu/nu) } \\
\text { nude mice[49] }\end{array}$ \\
\hline Lapatinib & $\begin{array}{l}\text { GW572016, } \\
\text { Tyverb®, } \\
\text { Tykerb® }\end{array}$ & $\begin{array}{l}\text { EGFR, } \\
\text { HER2, } \\
\text { ERK1/2, } \\
\text { AKT }\end{array}$ & + & + & $\begin{array}{c}\text { colorectal adenocarcinoma (S1- } \\
\text { M1-80), breast carcinoma } \\
\text { (MCF-7/ADR)[51], NSCLC } \\
\text { (A549-Taxol, DLKP-A)[50,52], } \\
\text { small-cell lung carcinoma (SBC- } \\
\text { 3/ETP, SBC-3/SN-38)[53], } \\
\text { prostate carcinoma (DU145- } \\
\text { TXR)[54] }\end{array}$ & $\begin{array}{l}\text { epidermoid carcinoma } \\
\text { KBv200 xenografts in } \\
\text { athymic nude mice[51]; } \\
\text { small-cell lung carcinoma } \\
\text { (SBC-3/ETP, SBC-3/SN-38) } \\
\text { xenografts in BALB/cA Jcl } \\
\text { nu/nu mice[53]; } \\
\text { prostate carcinoma DU145- } \\
\text { TXR xenografts in athymic } \\
\text { nude mice[54] }\end{array}$ \\
\hline \multicolumn{7}{|c|}{ VEGFR Inhibitors } \\
\hline Sorafenib & $\begin{array}{l}\text { BAY 43- } \\
9006, \\
\text { Nexavar }{ }^{\circledR}\end{array}$ & $\begin{array}{l}\text { VEGFR, } \\
\text { PDGFR, } \\
\text { RAF }\end{array}$ & + & + & $\begin{array}{c}\text { hepatocellular carcinoma } \\
\text { (SMMC7721/ADM, } \\
\text { BEL7402/ADM, HuH-7)[59] } \\
\text { gastric carcinoma } \\
\text { (SGC7901/DDP)[60] }\end{array}$ & $\begin{array}{c}\text { gastric carcinoma } \\
\text { SGC7901/DDP xenografts } \\
\text { in BALB/C nude mice[60] }\end{array}$ \\
\hline Sunitinib & $\begin{array}{l}\text { SU011248, } \\
\text { Sutent }{ }^{\circledR}\end{array}$ & $\begin{array}{l}\text { VEGFR, } \\
\text { PDGFR, c- } \\
\text { KIT, and } \\
\text { FLT3 }\end{array}$ & + & + & $\begin{array}{c}\text { gastric carcinoma } \\
\text { (SGC7901/VCR)[67], NSCLC } \\
\text { (A549/DDP)[68], ovarian } \\
\text { carcinoma tumor endothelial } \\
\text { cells (HOC-EC)[69] }\end{array}$ & $\mathrm{n} / \mathrm{a}$ \\
\hline Vandetanib & $\begin{array}{l}\text { ZD6474, } \\
\text { Caprelsa }{ }^{\circledR}\end{array}$ & $\begin{array}{l}\text { VEGFR, } \\
\text { EGFR, RET }\end{array}$ & + & - & $\begin{array}{c}\text { breast carcinoma (MCF- } \\
\text { 7/ADR), epidermoid carcinoma } \\
\text { (KBV200)[70], ovarian } \\
\text { carcinoma (IGROV1-DXR)[71] }\end{array}$ & $\mathrm{n} / \mathrm{a}$ \\
\hline Cabozanitinib & $\begin{array}{c}\text { XL184, } \\
\text { BMS907351, }\end{array}$ & $\begin{array}{l}\text { c-Met, } \\
\text { VEGFR, }\end{array}$ & + & - & hepatocellular carcinoma & $\begin{array}{l}\text { hepatocellular carcinoma } \\
\text { HepG2/ADR xenografts in }\end{array}$ \\
\hline
\end{tabular}




\begin{tabular}{|c|c|c|c|c|c|c|}
\hline & $\begin{array}{c}\text { Cabometyx }{ }^{\circledR}, \\
\text { Cometriq }{ }^{\circledR}\end{array}$ & $\begin{array}{l}\text { AXL, RET, } \\
\text { c-KIT, FLT- } \\
\text { 3, TIE-2, } \\
\text { TRKB }\end{array}$ & & & $\begin{array}{l}\text { (HepG2/ADR), breast carcinoma } \\
\text { (MCF-7/ADR), embryonic } \\
\text { kidney cells (HEK-293 } \\
\text { ABCB1), NSCLC (NCI- } \\
\text { H460/MX20)[72] }\end{array}$ & BALB/C nude mice[72] \\
\hline Regorafenib & $\begin{array}{l}\text { BAY 73- } \\
4506, \\
\text { Stivarga }{ }^{\circledR}\end{array}$ & $\begin{array}{l}\text { VEGFR, } \\
\text { TIE2, RET, } \\
\text { c-KIT, } \\
\text { PDGFR, } \\
\text { RAF }\end{array}$ & + & - & $\begin{array}{c}\text { colorectal adenocarcinoma } \\
\text { (SW620/ADR), embryonic } \\
\text { kidney cells (HEK-293 } \\
\text { ABCB1)[37] }\end{array}$ & $\begin{array}{l}\text { colorectal adenocarcinoma } \\
\text { SW620/ADR xenografts in } \\
\text { NCRNU-M nude mice[37] }\end{array}$ \\
\hline Nintedanib & $\begin{array}{l}\text { BIBF1120, } \\
\text { Vargatef® } \\
\text { Ofev } \AA\end{array}$ & $\begin{array}{l}\text { VEGFR, } \\
\text { FGFR, } \\
\text { PDGFR, } \\
\text { Src, Lck, } \\
\text { Lyn, and } \\
\text { FLT-3 } \\
\end{array}$ & + & - & $\begin{array}{c}\text { breast carcinoma (MCF- } \\
\text { 7/ADR), colorectal } \\
\text { adenocarcinoma (S1-M1-80), } \\
\text { promyelocytic leukemia (HL- } \\
\text { 60/ADR), hepatocellular } \\
\text { carcinoma (HepG2/ADR)[74] }\end{array}$ & $\mathrm{n} / \mathrm{a}$ \\
\hline \multicolumn{7}{|l|}{ ALK Inhibitors } \\
\hline Crizotinib & $\begin{array}{c}\text { PF-02341066, } \\
\text { Xalkori }{ }^{\circledR}\end{array}$ & $\begin{array}{l}\text { ALK, c- } \\
\text { MET, } \\
\text { HGFR, } \\
\text { ROS1 }\end{array}$ & + & - & $\begin{array}{l}\text { breast carcinoma (MCF- } \\
\text { 7/ADR), epidermoid carcinoma } \\
\text { (KBv200), promyelocytic } \\
\text { leukemia (HL-60/ADR), } \\
\text { colorectal adenocarcinoma (S1- } \\
\text { M1-80), embryonic kidney cells } \\
\text { (HEK-293 ABCB1)[75] }\end{array}$ & $\begin{array}{l}\text { epidermoid carcinoma } \\
\text { KBv200 xenografts in } \\
\text { BALB/C nude mice[75] }\end{array}$ \\
\hline
\end{tabular}

\subsection{Bcr/Abl Tyrosine Kinase Inhibitors}

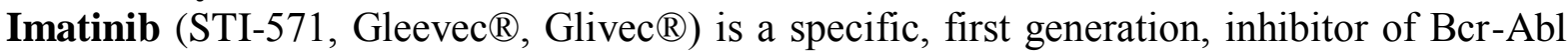
tyrosine kinase activity that also targets platelet-derived growth factor receptor (PDGFR) and mast/stem-cell growth factor receptor (c-KIT). As a first FDA (Food and Drug Administration) approved TKI, clinically used since 2001 [15], it was extensively studied regarding its interactions with $\mathrm{ABC}$ transporters. Although it was proven to be the high affinity substrate for P-gp [16], it was discovered that imatinib may also act as P-gp inhibitor, which is of high importance for its clinical application. This TKI was shown to completely or partially reverse resistance to various P-gp substrates, such as daunorubicin [17], romidepsin [18], vincristine, paclitaxel (PTX), etoposide, and actinomycin D [19]. However, the influence of imatinib on the reversal of resistance to doxorubicin (DOX), the most common P-gp substrate, is unclear. Mukai and collaborators reported no effect of imatinib on modulation of DOX resistance, while Sims and colleagues observed reversal of intrinsic and prevention of acquired resistance to DOX [19, 20]. Generally, the effect of imatinib on MDR reversal is attributed to its potential to modulate P-gp activity and expression. Imatinib downregulates its gene and protein expression [17, 20] and directly interacts with P-gp, causing inhibition of substrates efflux and their increased intracellular retention, therefore exerting similar effects as classical P-gp inhibitor verapamil [18, 20]. However, this P-gp modulatory effect is achieved only at higher doses [18, 21]. Other authors have shown that imatinib could modulate P-gp mediated resistance independently of Pgp overexpression mainly by the induction of apoptosis [22, 23]. Although- imatinib is mainly used for treatment of chronic myeloid leukemia (CML), its MDR reversal effects were also studied in other types of cancer, such as melanoma and breast carcinoma [20]. Moreover, in colon cancer anti-P-gp potential of imatinib was tested using novel platform for its delivery based on hyaluronan coated liposomes [24].

Since CML patients often develop resistance to imatinib, novel, second-generation, inhibitor of Bcr-Abl, PDGFR and c-KIT, Nilotinib (AMN107, Tasigna ${ }^{\circledR}$ ), was developed and approved for clinical practice in 2007. Nilotinib is more potent than imatinib in inhibiting Bcr-Abl tyrosine kinase activity and P-gp transporter function [13, 18, 21, 25]. It potentiates cytotoxicity and reverses resistance to common P-gp substrates, DOX, PTX, vincristine and colchicine, by blocking their efflux and enhancing intracellular accumulation [25-28]. This effect of nilotinib in 
modulating resistance to DOX and PTX was also shown in vivo on different MDR cancer models $[28,29]$. It is interesting to note that, in the study of Villar and colleagues, nilotinib showed synergistic antitumor effect with DOX, on the level of growth inhibition and apoptosis induction, in co-treatment and pretreatment and even had prolonged effect after drug withdrawal [25]. They observed that nilotinib downregulated basal cellular P-gp expression and DOX-induced upregulation of P-gp by blocking p38MAPK phosphorylation. However, in another study nilotinib was not shown to affect P-gp protein expression [26].

Dasatinib (BMS-354825, Sprycel®) is another second-generation multi-kinase inhibitor that is used to treat imatinib resistant or intolerant patients with Philadelphia chromosome-positive $(\mathrm{Ph}+)$ chronic myeloid leukemia (CML). It is most potently active against Bcr-Abl kinase and Src family kinases, including c-Src, Lck, Fyn, and Yes. Its role as P-gp inhibitor was also proven, although it is less potent than nilotinib and imatinib $[13,18]$. Nevertheless, in vitro study on breast carcinoma cells overexpressing P-gp, have shown that dasatinib potentiated sensitivity of those cells to DOX, inhibited DOX efflux by P-gp, increased intracellular DOX accumulation and enhanced DOX-induced apoptosis [30]. This effect was mediated by downregulation of P-gp mRNA and protein level, which was associated with the block of ERK phosphorylation. Recent studies have shown that dasatinib could also enhance PTX cytotoxicity and its intracellular accumulation in resistant breast carcinoma cell line (MCF-7/Adr) using novel, reductionsensitive micelles based, co-delivery system to load PTX and dasatinib [31]. Tsubaki and colleagues suggested that dasatinib exerts its inhibitory effect on P-gp protein and enhancement of drug sensitivity by suppressing Src activation in multiple myeloma cell lines [32].

Bosutinib (SKI-606, Bosulif $®$ ) is another dual Src/Abl TKI approved for use in imatinib resistant/intolerant CML. However, there are little data regarding its interaction with P-gp. It was reported in a single study that bosutinib could inhibit P-gp mediated fluorescent dye efflux but with less potency than nilotinib and dasatinib [13].

In order to overcome resistance or intolerance to imatinib and related TKIs, a thirdgeneration inhibitor, Ponatinib (AP24534, Iclusig®), was developed and approved for the treatment of $\mathrm{CML}$ and $\mathrm{Ph}+$ acute lymphoblastic leukemia, particularly those with severe resistance-related, BCR-ABLT315I mutation. Besides Bcr/Abl, ponatinib inhibits several other kinases, such as fms-like tyrosine kinase 3 (FLT3), fibroblast growth factor receptors (FGFRs), vascular endothelial growth factor receptors (VEGFRs) and angiopoietin (Tie2). Sen and associates have shown that ponatinib also has inhibitory effect on P-gp [33]. According to their study, ponatinib enhances uptake of P-gp substrates in P-gp overexpressing leukemic cells. It also decreases P-gp expression. Overall, it produced synergistic cytotoxic effect with daunorubicin and enhanced daunorubicin induced apoptosis, without effect on cell cycle.

\subsection{EGFR Tyrosine Kinase Inhibitors}

Gefitinib (ZD1839, Iressa $\left.{ }^{\circledR}\right)$ is the first EGFR tyrosine kinase inhibitor approved for cancer treatment, specifically advanced non-small cell lung cancer (NSCLC). Although it was initially used as a monotherapy, it was shown that gefitinib has potential to reverse resistance when combined with various P-gp substrates, DOX, PTX, docetaxel, vincristine and cisplatin [34-37]. Its MDR reversing effect considerably depends on the applied concentrations, ranging from no or partial effect when applied in low doses $[34,38]$ to moderate or pronounced effect when used in clinically relevant or high doses $[34,35]$. Similar to other TKIs, it directly interacts with P-gp and inhibits its function. It was shown that gefitinib increased intracellular accumulation of different fluorescent P-gp substrates (DOX, rhodamine 123, calcein-AM) in various cell lines overexpressing P-gp, such as canine or pig kidney epithelial cells and human lung and breast carcinoma cells $[35,36,39]$. Its P-gp modulating effect was also shown in vivo. Namely, 
gefitinib increased topotecan oral bioavailability and reduced its clearance in ABCB1 deficient mice [36]. It also reduced the tumor burden and weight, and also decreased ABCB1 mRNA level, when combined with cisplatinin-resistant human bladder carcinoma xenografted mice [40].

Erlotinib (OSI-774, Tarceva ${ }^{\circledR}$ ) is another orally administered inhibitor of the EGFR tyrosine kinase used to treat NSCLC, pancreatic cancer and several other cancer types. Similar to gefitinib, it potentiates cytotoxicity of various P-gp substrates, colchicine, PTX and vinblastine in P-gp-overexpressing human epidermoid carcinoma cell line [41], as well as DOX and etoposide in acute myelogenous leukemia cells [42]. However, in another in vitro model of acute myeloid leukemia, it was shown that erlotinib inhibitory effect towards P-gp is dependent on substrate type. Namely, it reversed resistance to vincristine and PTX but did not affect P-gp mediated resistance to DOX and even enhanced P-gp mediated resistance to mitoxantrone [43]. Generally, it was demonstrated that MDR reversing effect of erlotinib is mediated by direct interaction with P-gp and inhibition of its function, without effecting P-gp protein level [42, 43]. However, Lainey and colleagues observed that erlotinib reduced the amount of surface-exposed P-gp.

Development of resistance to gefitinib and erlotinib led to the design of second-generation EGFR inhibitors, such as afitinib and neratinib. Afatinib (BIBW 2992, Gilotrif $\AA$, Giotrif $\AA$ ) is an irreversible inhibitor of both the epidermal growth factor receptor (EGFR) and human epidermal receptor 2 (HER2) tyrosine kinases used as the first-line treatment of NSCLC patients with EGFR- mutations. Initial study on the afatinib interaction with ABC transporters showed that it did not interact with P-gp and didn't enhance the cytotoxicity of DOX in several DOX-resistant cell lines [44]. On the contrary, later reports revealed that afatinib had potential to reverse P-gpmediated resistance in P-gp overexpressing ovarian and lung cancer cells [45, 46]. Most importantly, docking simulation study of Wang et al. showed that afatinib directly binds to ATP binding domain of P-gp and therefore inhibits its efflux function. Such in silico analysis is the most rational initial approach, prior to in vitro and in vivo studies, for prediction of interaction between TKI and ABC transporters and evaluation of molecular mechanism of pump inhibition $[47,48]$. In addition, to interact with P-gp, afatinib reduces ABCB1 mRNA and protein level via down regulation of PI3K/Akt and by blocking mTOR phosphorylation, as well as through MAPK/p38 mediated inhibition of NF- $\mathrm{KB}[45,46]$. Reversal effect of afatinib was also proven in vivo. The combination of PTX and afatinib significantly delayed growth and induced regressions of P-gp overexpressing ovarian cell xenografts [45].

Neratinib (HKI-272, NerlynxTM) is another irreversible, small-molecule, tyrosine kinase inhibitor of both EGFR and Her-2 that also interacts with P-gp but with the opposite mechanism of action compared to afatinib [49]. Unlike afatinib, neratinib binds at large cavity of the transmembrane region of P-gp. Also, contrary to afatinib, it does not affect P-gp mRNA and protein level and does not alter Akt phosphorylation. Still, Zhao and colleagues demonstrated that neratinib improved sensitivity of P-gp overexpressing cell lines and primary leukemia blasts to main P-gp substrate anticancer drugs and reversed P-gp-dependent resistance in the nude mouse xenograft model.

Among all EGFR inhibitors, second-generation inhibitor lapatinib is the most extensively studied regarding its interactions with P-gp transporter. Lapatinib (INN, GW572016, Tyverb ${ }^{\circ}$, Tykerb $(\mathbb{R})$ is a multikinase inhibitor that reversibly blocks phosphorylation of EGFR andHER2/Neu as the main targets. As a P-gp inhibitor it is the most effective compared to the first-generation inhibitors, gefitinib and erlotinib [50]. Several studies have shown that lapatinib can restore chemosensitivity to many P-gp substrates (DOX, docetaxel, epirubicin, PTX, vinblastine, etoposide) in various resistant cells [50-53]. It is efficient in clinically relevant concentrations and may even have prolonged effect upon drug withdrawal [52]. As many other 
inhibitors, lapatinib directly interacts with P-gp but without effect neither on ABCB1 transcription nor on Akt and MAPK phosphorylation [51, 52]. Although Dai and co-authors did not report change in P-gp protein level upon lapatinib treatment, Dunne and colleagues suggested that lapatinib exerts its effect on P-gp protein synthesis [51, 52]. According to a study on resistant small cell lung carcinoma cells, lapatinib might also indirectly reduce P-gp function through HER2 dephosphorylation, causing Src activation, subsequently leading to caveolin-1 phosphorylation and its relocation that inhibits P-gp activity [53]. MDR modulating effect of lapatinib observed in vitro was also verified in vivo showing its potential to suppress growth of drug resistant xenografts in mice $[51,53]$. In addition, it was shown that a combination of lapatinib and PTX could be successfully delivered by lipopolymer micelles to prostate cancer cells in vitro and in vivo in order to overcome drug resistance [54]. However, Dai and collaborators reported that cotreatment with lapatinib and PTX could increase hepatotoxicity due to increased drug accumulation in hepatocytes as the consequence of P-gp inhibition by lapatinib [55].

Recently, a novel selective, irreversible third-generation EGFR TKI, osimertinib (AZD9291, Tagrisso $\left.{ }^{R}\right)$ was approved by FDA for the treatment of patients with metastatic EGFR T790M mutation-positive NSCLC. Osimertinib has theability to sensitize various P-gp-overexpressing cells to colchicine, vincristine, PTX and DOX, with similar effect to classical P-gp inhibitors [56-58]. According to docking simulations, osimertinib directly interacts with $\mathrm{P}$-gp transmembrane domain [58] and, as expected, impairs its function without influence on neither P-gp expression nor localization [56, 57]. P-gp modulating effects of osimertinib were also evidenced ex vivo on P-gp-overexpressing primary leukemia cells and in vivo as well [57].

\subsection{VEGFR Tyrosine Kinase Inhibitors}

Sorafenib (BAY 43-9006, Nexavar®) is a multikinase inhibitor for vascular endothelial growth factor receptor (VEGFR), platelet-derived growth factor receptor (PDGFR) and rapidly accelerated fibrosarcoma (RAF) kinases, therefore interfering with both angiogenesis and growth signaling. In addition, sorafenib restored chemosensitivity to conventional chemotherapeutics in drug-resistant hepatocellular carcinoma in vitro and gastric carcinoma in vitro and in vivo [59, 60]. This effect is achieved through the inhibition of ERK/MAPK and Akt signaling and decrease of ABCB1 gene and protein expression [59-61]. Moreover, sorafenib blocks function of $\mathrm{P}$-gp as observed through the increase in rhodamine 123 uptake and intracellular retention and inhibition of calcein-AM efflux [62, 63]. However, according to the report of Wei et al. sorafenib did not influence MDR mediated by P-gp in leukemia P-gp-overexpressing cells, since it did not interfere with P-gp activity nor its expression [64].

Sunitinib (SU011248, Sutent ${ }^{\circledR}$ ) is another multikinase inhibitor that intervenes with cellular proliferation and angiogenesis by targeting VEGFR, PDGFR, c-KIT, and FLT3. First studies on its interaction with P-gp showed no significant reversing effect on P-gp mediated drug resistance $[65,66]$. However, reports on drug resistant gastric and lung cancer cells, as well as on ovarian adenocarcinoma tumor endothelial cells, showed sunitinib's potential to sensitize cells to classic chemotherapeutics [67-69]. These studies suggested that sunitinib interferes with P-gp function resulting in increased intracellular level of rhodamine 123 and cytotoxic drugs. According to $\mathrm{Hu}$ and colleagues, sunitinib is even more potent in inhibiting P-gp function than sorafenib [63]. However, the data regarding its effect on P-gp expression are inconsistent, showing no influence on mRNA and protein level or their significant downregulation [67, 68]. Sunitinib's effect on Pgp is accompanied by the arrest in cell cycle and increase in apoptosis level, with the downregulation and inhibition of anti-apoptotic cellular components, as well as reduced phosphorylation of Scr, Akt, and ERK [67, 68]. 
Several other small-molecule compounds were developed as efficient VEGFR and other kinases inhibitors. Those include vandetanib (ZD6474, Caprelsa ${ }^{\circledR}$ ), cabozanitinib (XL184, BMS907351, Cabometyx ${ }^{\circledR}$, Cometriq ${ }^{\circledR}$ ), regorafenib (BAY 73-4506, Stivarga ${ }^{\circledR}$ ) and nintedanib (BIBF1120, Vargatef ${ }^{\circledR}$, Ofev $\left.{ }^{\circledR}\right)$. All these TKIs were shown to inhibit P-gp activity and successfully reverse resistance to standard chemotherapeutic drugs in various human P-gp overexpressing cancer cell lines [37, 70-74]. Specifically, they directly interacted with P-gp and increased intracellular accumulation of fluorescent P-gp substrates, but did not alter the expression or localization of the pump. In addition, regorafenib and nintedanib were reported to inhibit ATP-ase activity of P-gp [37, 74], while docking study showed that cabozanitinib share binding site on P-gp with classical P-gp inhibitor verapamil [72]. In vivo studies were conducted for cabozanitinib and regorafenib showing their potential to enhance antitumor effect of DOX and PTX in resistant P-gp overexpressing xenografts of hepatocellular and colorectal carcinoma, respectively, in nude mice $[37,72]$.

\subsection{ALK Tyrosine Kinase Inhibitors}

Anaplastic lymphoma kinase (ALK) is one of the kinases also recognized as a good candidate for targeting by small-molecule inhibitors in order to fight cancer. Several ALK tyrosine kinase inhibitors, including crizotinib (PF-02341066, Xalkori $\left.{ }^{\circledR}\right)$, ceritinib (LDK378, Zykadia ${ }^{\circledR}$ ) and alectinib (Alecensa ${ }^{\circledR}$ ), have been developed and approved for clinical practice. All three inhibitors were shown to block P-gp activity and enhance cytotoxicity of standard chemotherapeutics in several human cancer cell lines with P-gp mediated drug resistance [7577]. They directly interfere with P-gp function, therefore increasing the intracellular level of fluorescent P-gp substrates and inhibiting their efflux, but without effect on P-gp expression nor phosphorylation of c-Met, Akt, ERK1/2.

\subsection{Cyclin-dependent Kinases 4 and 6 (CDK4/6) Inhibitors}

Palbociclib (PD-0332991, Ibrance ${ }^{\circledR}$ ) and abemaciclib (LY2835219, VerzenioTM) are two clinically used CDK4/6 inhibitors that were recently reported to suppress P-gp function [78, 79]. Their anti-P-gp role in human cancers was tested in vitro and leads to increased sensitivity to common cytotoxic therapies in drug resistant cells with overexpressed P-gp. In case of abemaciclib, chemosensitizing effect was also proven in vivo showing synergistic effect with PTX in inhibiting growth of drug resistant xenografts without toxic side effects. As most-TKIs, palbociclib and abemaciclib block P-gp efflux function, thusincreasing intracellular retention of its substrates, without varying its expression on mRNA and protein level. Interestingly, their MDR modulating effect is completely independent from the inhibition of CDK4/6 and retinoblastoma pathway.

\subsection{Other Tyrosine Kinase Inhibitors}

There are several other clinically approved TKIs that were shown to interact with P-gp and reverse P-gp related drug resistance, such as B-RAF inhibitor, vemurafenib (PLX4032, Zelboraf ${ }^{\circledR}$ ), MEK inhibitor, trametinib (GSK1120212, Mekinist ${ }^{\circledR}$ ) and BTK inhibitor, ibrutinib (Imbruvica ${ }^{\circledR}$ ). However, there are only individual studies for these inhibitors demonstrating their antagonizing effect on P-gp function in vitro and in vivo [80-82] and they are summarized in Table 1.

Moreover, there is a large number of TKIs that are in different phases of preclinical or clinical trials and that have potential to overcome MDR and modulate P-gp activity [83-86]. List of such TKIs is constantly growing, emphasizing thesignificance of their multifunctionality in anticancer treatment. 


\section{NATURAL-BASED COMPOUNDS}

Several plant-based compounds and extracts, as well as compounds found in other natural sources, have been shown to inhibit P-gp and modulate MDR [87, 88]. In addition to P-gp inhibitory activity, some of these compounds act as inhibitors of other targets that are, directly or indirectly, responsible for the occurrence of MDR phenotype in cancer cells. Herein, we address the origin, function, and mechanism of action of dual target natural compounds with MDR reversal potential. The information about anti-P-gp activity and chemosensitization potential of most important compounds is summarized in Table 2.

Table 2. Natural and natural-based compounds with multi-targeting and anti-P-gp potential

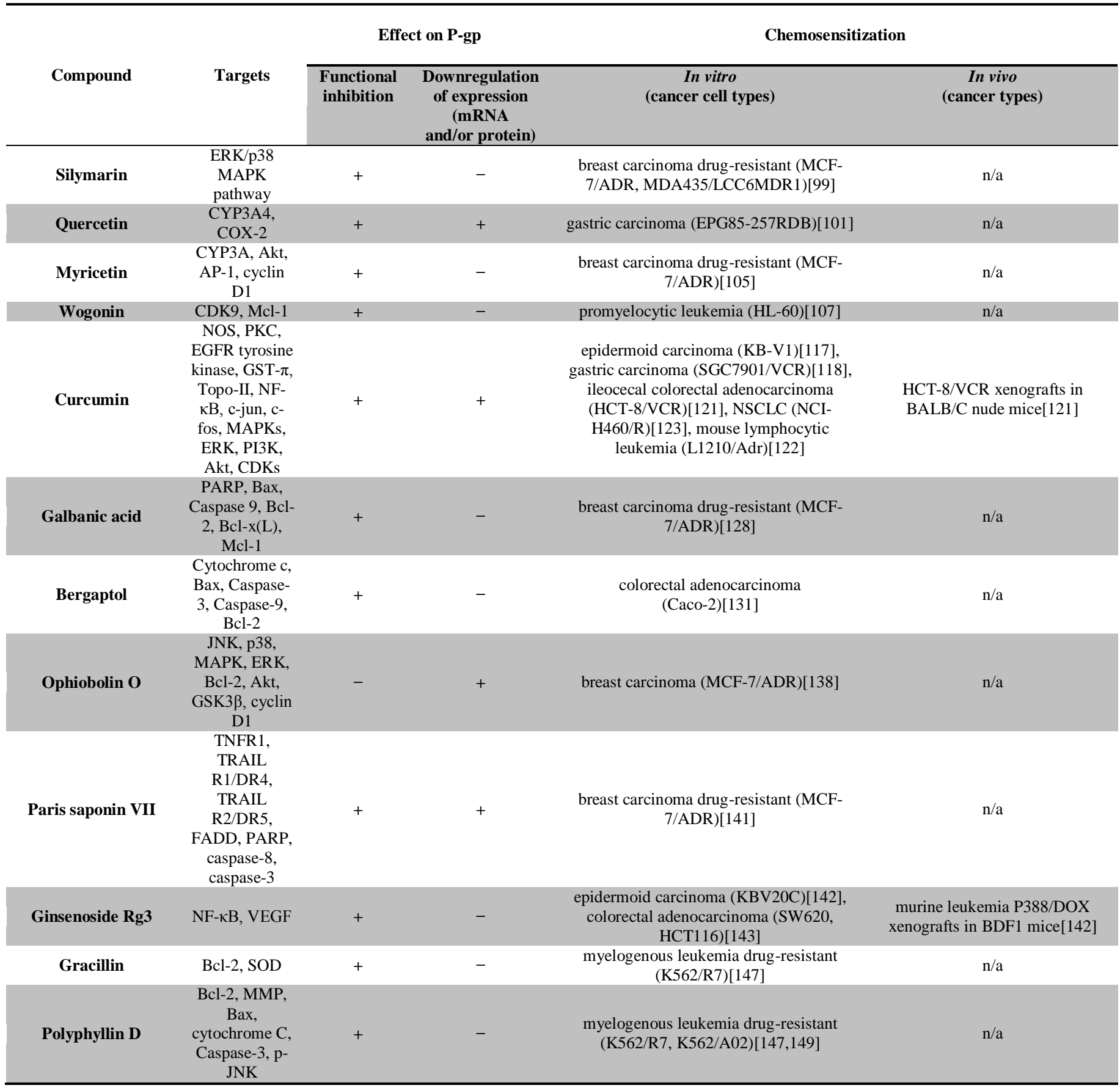




\begin{tabular}{|c|c|c|c|c|c|}
\hline Glaucine & $\begin{array}{l}\text { MMP-9, NF- } \\
\kappa B\end{array}$ & + & - & $\begin{array}{l}\text { breast carcinoma drug-resistant (MCF- } \\
\text { 7/ADR)[152] }\end{array}$ & $\mathrm{n} / \mathrm{a}$ \\
\hline Cepharanthine & $\begin{array}{c}\text { PI3K/Akt } \\
\text { pathway, Bax, } \\
\text { Bcl-2 Caspase- } \\
\text { 3, PARP, Bcl- } \\
\text { xL c-Myc, } \\
\text { cyclin D1, } \\
\text { Hsp90 } \alpha\end{array}$ & + & + & myelogenous leukemia (K562)[156] & $\mathrm{n} / \mathrm{a}$ \\
\hline Tetrandrine & Akt, ERK & + & - & $\begin{array}{c}\text { colorectal adenocarcinoma (HCT-15, } \\
\text { Caco-2)[161,162], T lymphoblastic } \\
\text { leukemia (CEM/ADR5000)[162] }\end{array}$ & $\mathrm{n} / \mathrm{a}$ \\
\hline Fangchinoline & $\begin{array}{l}\text { PI3K, Akt, } \\
\text { Bax, Bcl-2, } \\
\text { FAK }\end{array}$ & + & - & $\begin{array}{c}\text { colorectal adenocarcinoma (HCT-15, } \\
\text { Caco-2)[161,162], T lymphoblastic } \\
\text { leukemia (CEM/ADR5000)[162] }\end{array}$ & $\mathrm{n} / \mathrm{a}$ \\
\hline Indole-3-carbinol & $\begin{array}{l}\text { Bax, Bcl-2, } \\
\quad \mathrm{NF}-\kappa \mathrm{B}\end{array}$ & - & + & $\begin{array}{l}\text { myelogenous leukemia drug-resistant } \\
\text { (K562/R10)[167] }\end{array}$ & $\mathrm{n} / \mathrm{a}$ \\
\hline Cannabidiol & $\begin{array}{l}\text { Akt, mTOR, } \\
\text { Cyclin D1, } \\
\text { Beclin1 and } \\
\text { Bcl-2 }\end{array}$ & + & + & colorectal adenocarcinoma (Caco-2)[172] & $\mathrm{n} / \mathrm{a}$ \\
\hline
\end{tabular}

\subsection{Polyphenols}

Multiple plant derived polyphenolic compounds, such as flavonoids and stilbenes or their synthetic derivatives, have been reported to modulate P-gp activity [89].

(-)-Epigallocatechin-3-gallate (EGCG), the most abundant polyphenolic catechin in green tea, has been shown to downregulate P-gp in a tamoxifen resistant MCF-7 cell line [90]. In addition, EGCG has been reported to inhibit Hsp90 function by impairing Hsp90 association with co-chaperones in pancreatic cancer cell line Mia Paca-2 [91].

8-Prenylnaringenin, a potent phytoestrogen isolated from hops (Humulus lupulus), was shown to strongly inhibit P-gp activity in human erythrocytes as well as human adenocarcinoma cell line [92]. This prenylflavonoid is also a strong inhibitor of human estrogen receptor ER $\alpha$ and ERß [93].

Icaritin, first isolated from the Chinese herb Herba epimedii, demonstrated anticancer activity against HepG2 liver cancer cell line. This flavonoid significantly increased the intracellular accumulation of DOX and decreased the expression of the MDR1 gene in a multiple drug-resistant HepG2 HepG2/ADR cell line compared with drug-sensitive HepG2 cells and also significantly downregulated the expression of P-gp [94]. In addition, Wu et al. found that icaritin exerted anti-melanoma activities partially due to inhibition of fatty acid synthase signaling [95].

Baicalein, a flavonoid isolated from Scutellariae radix, caused inhibition of the P-gp transporter in the small intestine [96]. In addition to its ability to act as the efflux pump inhibitor, baicalein has also been reported to inhibit Src tyrosine kinase [97].

Silymarin has been reported to inhibit P-gp mediated efflux in colon cancer Caco-2 cell line [98], potentiate the cytotoxicity of DOX in P-gp expressing cells through modulation of P-gp ATPase activity [99], as well as ERK/p38 MAPK pathway in human bronchial epithelial cells [100].

Another flavonoid, quercetin, was reported to chemosensitize P-gp-expressing gastric carcinoma EPG85-257RDB cell line by downregulating P-gp expression and inhibiting drug efflux [101]. Quercetin was also reported to significantly inhibit the CYP3A4 activity both in vitro [102] and in vivo [103] and increase the bioavailability of DOX. In addition, quercetin exhibited potent COX-2 inhibitory activity and induced apoptosis and cell cycle block in vitro in human oesophageal adenocarcinoma OE33 cell line [104].

Myricetin significantly increased rhodamine 123 accumulation in P-gp-overexpressing MCF7/ADR cells. It also increased DOX absorption in the gastro-intestinal tract via P-gp inhibition and reduced DOX metabolism due to CYP3A inhibition in the small intestine and liver [105]. 
Another study showed that myricetin inhibited the phosphorylation and kinase activity of Akt via binding to the ATP-binding site. Myricetin also inhibited Akt-mediated activator protein-1 (AP1) transactivation, cyclin D1 expression and cell transformation [106].

Wogonin (5,7-dihydroxy-8-methoxyflavone), a flavone originating from roots of Scutellaria baicalensis Georgi, impaired the function of P-gp and triggered etoposide-induced apoptosis in human promyelocytic leukemia cells HL-60 [107]. Polier et al. demonstrated that wogonin is also an inhibitor of cyclin-dependent kinase 9 (CDK9) and blocks phosphorylation of the carboxy-terminal domain of RNA polymerase II at Ser2 which leads to reduced RNA synthesis and subsequently rapid downregulation of myeloid cell leukemia 1 (Mcl-1) protein resulting in apoptosis induction in cancer cells [108]. Pull-down and in silico docking studies demonstrated that wogonin directly binds to CDK9. Moreover, wogonin preferentially inhibited CDK9 in leukemic cell lines compared to normal lymphocytes.

Resveratrol (3,5,4'-trihydroxy-trans-stilbene) enhanced the cytotoxicity of docetaxel and DOX in solid tumors by inhibiting the P-gp efflux and downregulating the MDR1 gene [109]. In addition, it was reported that resveratrol directly binds to cyclooxygenase-2 (COX-2) and thus prevents the formation of human colon adenocarcinoma HT-29 colonies in soft agar [110].

A study has demonstrated that polyphenolic compounds caffeic acid phenetyl ester, licochalcone A, and anacardic acid, have dual inhibitory effects on the P-gp drug efflux transporter and NF-kB activation in human MDR1 gene-transfected KB/MDR1 cells [111].

Coniferyl ferulate, isolated from the root of Angelica sinensis, decreased expression of P-gp mRNA in the MDR positive B-MD-C1 (ADR+/+) cell line and also exhibited a strong inhibition of key MDR enzyme glutathione S-transferase in human placenta in a concentration-dependent manner [112].

Methylhirsutanonol, a diarylheptanoid extracted from the bark of Alnus glutinosa, suppressed P-gp functioning in P-gp overexpressing human NSCLC NCI-H460/R cell line [113]. Another study showed that methylhirsutanonol isolated from the leaves of Alnus japonica Steud inhibited NO production and expression of iNOS protein and mRNA in a dose-response manner and attenuated NF- $\kappa \mathrm{B}$ activation [114].

Curcumin, a polyphenol obtained from the dried rhizomes of Curcuma longa, has been shown to interact with several molecular targets implicated in carcinogenesis and MDR. More specifically, curcumin has been described as an inhibitor of the P-gp function in numerous in vitro and in vivo models [115-119]. In addition, curcumin has been reported to inhibit the expression of P-gp at both protein and mRNA level [117, 118, 120-123].

Curcumin was shown to inhibit numerous other targets responsible for the incidence of MDR in cancer cells including inducible nitric oxide synthase, protein kinase $\mathrm{C}$ and EGF-receptor tyrosine kinase [124]. The expression of MDR-related genes, gst- $\pi$ and topo II $\alpha$, was shown to be altered by curcumin treatment [123]. Curcumin was also reported to inhibit the NF- $\kappa \mathrm{B}$ activation and the expressions of oncogenes such as c-jun, c-fos, MAPKs, ERK, PI3K, Akt and CDKs and might suppress tumor promotion through blocking signal transduction pathways in the target cells [125].

\subsection{Coumarins}

Various coumarins were studied for their ability to inhibit P-gp and reverse multidrug resistance.

GUT-70 is a tricyclic coumarin isolated from the stem bark of Calophyllum brasiliense. A study showed that GUT-70 strongly inhibited drug efflux in the P-gp overexpressing human leukemic cell line K562/D1-9 in a concentration and time-dependent manner [126]. GUT-70 
was also shown to have pronounced antiproliferative effects in mantle cell lymphoma cell lines through Hsp90 inhibition [127].

Galbanic acid and farnesiferol A, sesquiterpene coumarins from Ferula szowitsiana and Ferula persica roots, respectively, significantly inhibited P-gp activity in DOX resistant MCF7/ADR cells [128]. Farnesiferol A was shown to inhibit the P-gp transporter more efficiently than verapamil. A study revealed that galbanic acid also cleaved poly (ADP-ribose) polymerase (PARP), activated Bax and caspase 9, attenuated the expression of Bcl-2, Bcl-x(L), and Myeloid cell leukemia 1 (Mcl-1) in H460 cells which suggests that galbanic acid induces apoptosis via caspase activation and Mcl-1 inhibition [129]. Farnesiferol A was reported to exhibit weak inhibitory effects on matrix metalloproteinases expression [130]. FC726, a furanocoumarin from grapefruit juice, strongly inhibited uptake of vinblastine by Caco-2 cells due to P-gp inhibition as well as the activity of cytochrome P450 3A4 [131].

Bergaptol found in grapefruit juice inhibited the P-gp transporter and increased the steadystate uptake of $\left[{ }^{3} \mathrm{H}\right]$-vinblastine by Caco-2 cells [131]. It was also reported that bergaptol treatment increased the cytosolic cytochrome c, Bax, cleaved caspase- 3 and cleaved caspase- 9 expressions and decreased in Bcl-2 expression in human breast cancer MCF-7 cells [132].

\subsection{Terpenoids}

Terpenoids have been shown to possess significant P-gp inhibitory effect as well as other anticancer mechanisms. Based on their structure they are classified into monoterpenoids, sesquiterpenoids, diterpenoids and triterpenoids.

Artemisinin, a sesquiterpene lactone from the sweet wormwood plant Artemisia annua, and its bioactive derivatives were shown to possess strong anticancer effects in numerous human cancer cell models [133]. Artemisinin has also been observed to decrease MDR in cancer patients, partly through inhibiting glutathione S-transferase activity [134]. Two of its derivatives, SM616 and GHP-AJM-3/23 were reported to inhibit P-gp activity in P-gp overexpressing CEM/ADR5000 leukemia cells, sensitive CCRF-CEM leukemia cells, and porcine brain capillary endothelial PBCEC cells [135].

Euphodendrophane $\mathbf{A}$ and euphodendrophane B, two jatrophanes isolated from the Euphorbia dendroides L., exerted a strong reversal potential resulting from the inhibition of P-gp transport in MDR NCI-H460/R cells [136]. Treatment with these compounds caused significantly higher accumulation of rhodamine 123 in the NCI-H460/R cell line, compared to the effect of the standard P-gp inhibitor, verapamil. Euphodendrophane A also stimulated purified tubulin assembly in vitro and microtubule-interacting activity was achieved with euphodendrophane A concentrations that effectively inhibit cell growth [137].

Ophiobolin O, a sesterterpene isolated from Aspergillus ustus, was found to reverse MCF7/ADR resistance to DOX by inhibiting the activity of the MDR1 gene promoter [138]. Ophiobolin O was also reported to initiate apoptosis in human MCF-7 breast cancer cells [139]. This compound triggered the activation of JNK, p38 MAPK and ERK, and the degradation of Bcl-2 phosphorylation. It was also shown to decrease the phosphorylation level of Akt and GSK3 $\beta$ and downregulation of cyclin D1 [140].

\subsection{Saponins}

Saponins are a class of chemicals found in certain plant families and they can be classified into steroidal and triterpenoidal. Various saponins have been found to exibit P-gp reversal potential.

Paris saponin VII, derived from Trillium tschonoskii Maxim, inhibited cell viability, activated apoptosis and modulated drug resistance of MCF-7/ADR cells in a dose dependent 
manner. Treatment of MCF-7/ADR cells with this steroid saponin increased TNFR1, TRAIL R1/DR4, TRAIL R2/DR5, FADD expression, and activated PARP, caspase-8, and caspase-3. Pgp expression and activity were also reduced [141].

Steroidal saponin ginsenoside Rg3, isolated from Panax ginseng, stimulated rhodamine 123 accumulation in drug-resistant KBV20C cells, inhibited [3H]vinblastine efflux and reversed MDR to DOX, colchicine, vincristine and VP-16 [142]. Rg3 also competed with [3H]azidopine for binding to P-gp. Additionally, Rg3 caused significant inhibition of NF- $\kappa \mathrm{B}$ activity and enhanced the susceptibility of colon cancer cells to docetaxel [143] and inhibited their migration [144]. Ginsenoside $\operatorname{Rg} 3$ also acts as VEGF inhibitor in the treatment of NSCLC [145] and inhibits autophagy in hepatocellular carcinoma cells sensitizing them to DOX [146].

Saponins gracillin and polyphyllin D, isolated from the root of Paris polyphylla (Trilliaceae), exhibited the ability to inhibit P-gp-mediated drug efflux in K562/R7 cells [147]. Gracillin also induced apoptosis in HL60 human leukemic cell line via oxidative stress and cell cycle arrest, dramatically decreased mRNA level of Bcl-2 and superoxide dismutase activity [148]. Polyphyllin D induced apoptosis via the mitochondrial apoptotic pathway in K562/A02 human leukemia drug-resistant cells as evidenced by decreased Bcl-2 expression levels, disruption of MMP and increased Bax, cytochrome C and cleaved-caspase-3 levels [149]. Polyphyllin D was also reported to trigger apoptosis, significantly upregulate the expression of Bax, caspase-3, and p-JNK, and downregulate Bcl-2 expression in U87 human glioma cells [150].

\subsection{Alkaloids}

Alkaloids represent a group of natural compounds that contains one or more basic nitrogen atoms. Numerous alkaloids have been shown to interact with and inhibit P-gp mediated drug efflux.

Glaucine was originally isolated from the stems of Corydalis yanhusuo. This isoquinoline alkaloid was shown to inhibit P-gp mediated efflux and activate ATPase activities of transporters [151]. Glaucine also suppressed migration and invasion in breast cancer cells MCF-7 and MDAMB-231 by inhibiting MMP-9 gene expression through the suppression of NF- $\kappa \mathrm{B}$ activation [152].

Cepharanthine, a bisbenzylisoquinoline alkaloid, was extracted from Stephania cepharantha Hayata. Cepharanthine reversed MDR directly interacting with P-gp and possibly disturbing the plasma membrane function by binding to phosphatidylserine in the membrane [153-155]. A study showed that cepharanthine effectively reversed resistance in human chronic myelogenous leukemia cell line K562 and enhanced their sensitivity and apoptosis induced by DOX and vincristine [156]. Cepharanthine hydrochloride reversed $\mathrm{P}$-gp-mediated MDR in human ovarian carcinoma A2780/Taxol cells via inhibition of the PI3K/Akt signaling pathway [157]. Cepharanthine also induced apoptosis in human NSCLC H1299 and A549 cells through reactive oxygen species and mitochondrial dysfunction. Cepharanthine triggered apoptosis via the upregulation of Bax, downregulation of Bcl-2 and significant activation of caspase-3 and PARP [158]. In SaOS2 cells, cepharanthine triggered cell cycle arrest and apoptosis significantly inhibited the expression of target genes of STAT3, including the anti-apoptotic gene Bcl-xL and the cell cycle regulators c-Myc and cyclin D1 [159]. It was also demonstrated that cepharanthine interacts with and inhibits heat shock protein $90 \alpha(\mathrm{Hsp} 90 \alpha)$ [160].

Tetrandrine and fangchinoline are bis-benzylisoquinoline alkaloids from the root of Stephania tetranda. A study found that both compounds sensitized P-gp overexpressing colorectal cancer HCT-15 cells to PTX and enhanced rhodamine123 accumulation [161]. Another report showed that tetrandrine and fangchinoline increased intracellular accumulation of rhodamine123 and inhibited its efflux in Caco-2 and CEM/ADR5000 cancer cells and exhibited 
a strong synergistic cytotoxic effect with DOX [162]. Tetrandrine treatment also resulted in a downregulation of Akt and ERK phosphorylation in time- and concentration-dependent manner in A549 human lung carcinoma cells, suggesting that tetrandrine selectively inhibits cell proliferation by blocking Akt activation and increases apoptosis by inhibiting ERK [163]. Fangchinoline effectively suppressed proliferation and invasion of SGC7901 cell line by inhibiting the expression of PI3K and its downstream pathway [164]. Furthermore, fangchinoline inhibited breast cancer cell proliferation by inducing apoptosis via the mitochondrial apoptotic pathway and decreasing phosphorylated Akt [165]. Fangchinoline increased the expression of the proapoptotic protein Bax and decreased the expression of the antiapoptotic Bcl-2. In human lung cancer A549 cells, fangchinoline targeted FAK and suppressed FAK-mediated signaling pathway [166].

Indole-3-carbinol is a glucosinolate found in high concentrations in vegetables of the Brassica family. A study showed that treatment with indole-3-carbinol downregulated P-gp levels in vinblastine-resistant human leukemia (K562/R10) cells suggesting it could be used as a novel modulator of P-gp [167]. In another study, indole-3-carbinol was also found to upregulate Bax, downregulate Bcl-2 and NF- $\kappa$ B in PC-3 cells [168].

\subsection{Other Natural-Based Compounds}

Gambogic acid is a xanthonoid derived from the resin of Garcinia hanburyi. It was shown to increase the cytotoxicity of docetaxel and DOX in MCF-7/ADR cells by inhibiting the P-gp protein via degradation by proteasome pathway [169]. Gambogic acid was also reported to inhibit Hsp90 in MCF-7 and Sk-Br3 cells [170] and induced apoptosis in human breast cancer cells MCF-7 by reducing bcl-2 expression via p53 [171].

Cannabinol and cannabidiol, phytocannabinoids derived from Cannabis sativa, have been reported to inhibit P-gp mRNA expression in MCF-7/P-gp cells and enhance the intracellular accumulation rhodamine 123 and DOX in Caco-2 and LLC-PK1/MDR1 cells [172, 173]. Cannabidiol induced programmed cell death in breast cancer cells by coordinating the cross-talk between apoptosis and autophagy [174]. Cannabidiol inhibited AKT and mTOR signaling by decreasing the levels of phosphorylated mTOR and cyclin D1. It also inhibited the association between beclin1 and Bcl-2 in MDA-MB-231 breast cancer cells.

Sulfinosine, a purine nucleoside analog, was shown to inhibit both $\mathrm{P}$-gp expression and activity in MDR cancer cells [123, 175-177]. Sulfinosine also induced caspase-dependent apoptotic cell death and autophagy in NCI-H460/R and U87-TxR glioblastoma cells. This compound also decreased the expression of mRNA and protein levels of VEGF and modulated its secretion.

Antimicrobial cationic peptide NK-2, an internal fragment of porcine NK-lysin, was reported to discriminate and preferentially eliminate P-gp overexpressing NSCLC NCI-H460/R and colorectal carcinoma DLD1-TxR cells [178]. NK-2 co-localized with P-gp on the MDR cancer cell membrane and decreased P-gp transport activity. Positively charged NK-2 also induced lysis of negatively charged cancer cell plasma membrane in a "carpet-like" manner.

\section{MICROTUBULE INTERACTING AGENTS AS DUAL INHIBITORS}

Microtubule targeting agents (MTAs) that disrupt microtubule/tubulin dynamics are widely used in cancer therapy. Microtubules, a major type of cytoskeletal filament in cells, are formed from tubulin subunits, $\alpha, \beta$-heterodimer that forms the core of the microtubule [179]. Since microtubules play crucial roles in the regulation of the mitotic apparatus, disruption of microtubules lead to cell cycle arrest in G2/M phase, the formation of abnormal mitotic spindles, and consequently to apoptosis of cancer cells [180]. Clinically important MTAs can be 
subdivided into two broad groups according to their effect on microtubules: microtubule stabilizing agents, such as taxanes, epothilones, discodermolide, laulimalide, and eleutherobins, and microtubule destabilizing agents such as Vinca alkaloids, colchicine, cryptophycins, and combretastatins [181, 182]. In spite of the initial clinical success of MTAs in cancer treatment, the efficacy of these agents has been compromised by the development of drug resistance. Increased expression of P-gp and changes in $\beta$-tubulin isoforms' expression are the most common mechanisms involved in MTAs' resistance $[183,184]$. Therefore, identification of new anticancer drugs that are able to overcome the problem of resistance to clinically approved MTAs is emerging.

The synthetic compound CDBT (Figure 1) is a novel microtubule and heat shock protein 90 (HSP90) dual inhibitor [185]. It was shown that CDBT inhibited tubulin polymerization, which caused disruption of microtubule network, cell cycle arrest at the G2/M phase and apoptosis in non-small cell lung carcinoma (NSCLC) cells. CDBT selectively binds to tubulin at the colchicine binding site and thus inhibits tubulin polymerization in a similar manner as colchicine. CDBT also binds and inhibits HSP90, a highly abundant and ubiquitous molecular chaperone which plays an essential role in folding, translocation, and proteolytic turnover of proteins involved in cell growth, cell differentiation, and cell survival. In the last ten years, it has become a major therapeutic target for cancer treatment [186]. By inhibiting HSP90 chaperone activity, CDBT induces degradation of HSP90 target proteins CRAF-1, ERBB2 and phosphorylated Akt. However, CDBT's affinities towards microtubules and HSP90 are moderate compared to known MTA colchicine and HSP90 inhibitor 17-DMAG. CDBT also displayed less growth inhibitory effect in normal cells compared to NSCLC cells in vitro and in vivo [185]. Further study by Zhang et al. [187] demonstrated that CDBT was not a P-gp substrate, which allowed it to evade P-gp-mediated efflux. This is a very important feature of CDBT considering that many anticancer drugs, including MTAs and HSP90 inhibitors are substrates for P-gpSignificantly, CDBT showed similar growth inhibitory effect between P-gp overexpressing cancer cells and their parental cells (human NSCLC and breast adenocarcinoma cells). CDBT also inhibited tumor growth in human resistant NSCLC xenograft model with the same efficacy as in parental NSCLC xenograft model, showing no- toxicity in normal tissues [187]. Low toxicity is another important feature of CDBT. Therefore, these studies suggested CDBT as a promising anticancer agent beneficial for the treatment of drug-resistant tumors. 
<smiles>CN(C)c1ccc(/C=C2/S/C(=N/c3ccccc3Cl)NC2=O)cc1</smiles>

CDBT

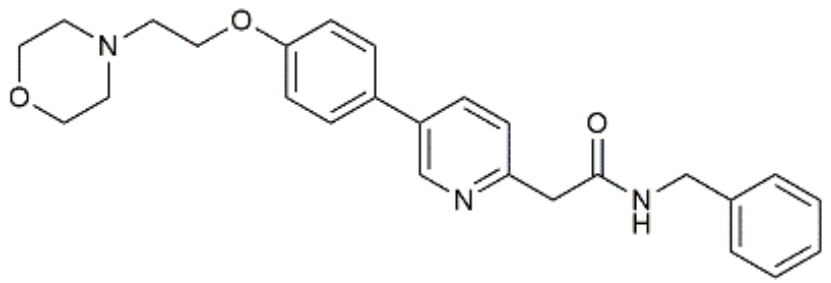

KX-01<smiles>CCCCC(C#CC(=O)OC)O/C=C/C(=O)OC</smiles>

DTA0100<smiles>COc1cc(OC)cc(C(=CC#N)c2cc(OC)cc(OC)c2)c1</smiles>

CC-5079<smiles>COc1cccc2c1ccc1nc3cccc(C(=O)N[C@@H](C)CN(C)C)c3nc12</smiles>

XR11576<smiles>COc1cc(/C=C2\CC/C(=C\c3ccc(O)c(OC)c3)C2=O)ccc1O</smiles>

BPROY007

Figure 1. Microtubule and topoisomerase dual inhibitors active against P-gp

CC-5079 (Figure 1) is a novel, synthetic antimitotic and anti-TNF- $\alpha$ compound with a diarylalkene structure [188]. It was shown that CC-5079 binds directly to tubulin thereby preventing polymerization of purified tubulin in vitro. This compound also inhibited microtubule polymerization in cancer cells, which caused cell cycle arrest in G2/M phase, and induced apoptosis. Competitive binding studies showed that CC-5079 binds to tubulin at colchicine binding site [188]. Moreover, CC-5079 increased phosphorylation of Cdc25C phosphatase, an important mitotic regulatory protein, and induced accumulation of cyclin B [188]. The changes in Cdc25C and cyclin B were followed with the appearance of phosphorylated polypeptides found only in mitotic cells [188]. CC-5079 also increased phosphorylation of anti-apoptotic protein bcl-2 and expression of p53 and p21 [188]. However, unlike other MTAs, CC-5079 remained active against P-gp overexpressing cancer cells. Cytotoxicity test and cell cycle analysis revealed that CC-5079 had the same efficiency in MDR cancer cells and their sensitive counterparts [188]. Therefore, CC-5079 may circumvent P-gp-mediated drug resistance. Furthermore, CC-5079 inhibited TNF- $\alpha$ secretion from human peripheral blood mononuclear cells [188]. TNF- $\alpha$ is a cytokine that may contribute to the pathogenesis of cancers by promoting growth of cancer cells, inhibiting their apoptosis and allowing cancer cells to escape immune surveillance $[189,190]$. Inhibitory effect of CC-5079 on TNF- $\alpha$ production is related to its inhibition of phosphodiesterase type 4 enzymatic activity, an essential cAMP-metabolizing enzyme in immune and inflammatory cells [191]. In a view of these dual inhibitory effects, CC5079 represents a novel anticancer drug that might be effective for the treatment of malignant diseases independent of their MDR status. 
KX-01 (clinical-reference, KX2-391, Figure 1) is a novel peptidomimetic compound that exhibits dual action as c-Src and microtubule inhibitor. c-Src is a non-receptor tyrosine kinase that has been associated with cancer cell proliferation, motility, migration/invasion, angiogenesis and metastasis $[192,193]$. KX-01 was developed to bind and inhibit the activity of c-Src kinase and its downstream target, focal adhesion kinase (FAK) [194, 195]. KX-01 currently completed phase II trial for prostate cancer as well as phase Ib trial for acute myeloid leukemia [196, 197].

Furthermore, study by Anbalagan et al., showed that KX-01 could be effective in the treatment of ER/PR/HER2-negative breast cancer [198]. Namely, KX-01 inhibited activity of cSrc and its downstream mediator FAK in tumor xenografts that was followed by reduced proliferation and angiogenesis and increased apoptosis. In addition to c-Src inhibition, the study by Anbalagan et al. also showed that $\mathrm{KX}-01$ inhibited microtubule polymerization in human ER/PR/HER2-negative breast cancer cells both in vitro and in vivo. This dual activity of KX-01 may present an additional value for treatment of ER/PR/HER2-negative breast cancer subtype that is intrinsically more resistant than other breast cancer subtypes [199].

\section{TOPOISOMERASE I AND II DUAL INHIBITORS}

DNA topoisomerases are essential enzymes that regulate the topological state of DNA during cellular processes such as replication, transcription, recombination, and chromatin remodeling [200-203]. Topoisomerase I relaxes DNA supercoiling through cycles of cleavage and relegation. Topoisomerase I introduces transient single strand DNA breaks by forming reversible topoisomerase I/DNA covalent complex [204, 205]. Topoisomerase II catalytically cleaves both strands of the DNA duplex and mediates the passage of another double strand DNA through the transiently broken duplex. This process generates transient topoisomerase II/DNA covalent complexes and DNA double strand breaks that are rapidly repaired [206, 207].

Topoisomerase inhibitors are widely used in cancer treatment. Inhibitors of topoisomerase I stabilize topoisomerase I/DNA cleavage complexes, prevent the relegation of DNA and convert DNA single strand breaks into irreversible and lethal double strand breaks [208]. Camptothecin was the first discovered topoisomerase I inhibitor, but its severe side effects prevented any clinical utility [209]. Two camptothecin derivatives, topotecan and irinotecan have been approved for the treatment of ovarian and lung cancers, and colorectal cancer, respectively [210].

Topoisomerase II inhibitors enhance the level of DNA double strand breaks, thereby activating DNA damage response, and subsequently leading to cell cycle arrest and apoptosis [211]. The most important subclasses of topoisomerase II inhibitors in the clinics are epipodophyllotoxins (etoposide and teniposide) and anthracyclines (daunorubicin, doxorubicin, epirubicin and idarubicin) [212].

Although topoisomerase inhibitors are among the most commonly used anticancer drugs, development of drug resistance often inhibits their clinical efficacy [204, 213]. One of the most common mechanisms of resistance to topoisomerase inhibitors is a decreased expression of their specific target [214]. Furthermore, the resistance to topoisomerase I inhibitors is often compensated by increase in the level of topoisomerase II expression and vice versa. Therefore, it has been suggested that such resistance may be overcome by the ability of drugs to target both topoisomerase I and II simultaneously. However, simultaneous or sequential exposure of cancer cells to etoposide and to topotecan or irinotecan demonstrated an antagonistic rather than synergistic effect $[215,216]$. In this regard, a single compound able to inhibit both topoisomerase I and II may present an advantage and reduce toxic side effects.

Tafluposide (F11782) is a novel dual catalytic inhibitor of topoisomerases I and II [217]. This epipodophyllotoxin derivative has shown broad anticancer activity against human cancer cell lines and tumor xenografts derived either from haematological or solid tumors [218, 219]. 
Tafluposide was also identified as a potent inhibitor of nucleotide excision repair [220]. More recently, study by Kluza et al. showed that tafluposide could be a potent pro-apoptotic agent [221]. Tafluposide, induced DNA strand breaks causing mitochondrial perturbations and leading to the activation of the pro-apoptotic cascades in HL-60 human promyelocytic leukemic cells.

Batracylin (NSC3208468) was synthesized as a structural analogue of ellipticine, a known inhibitor of topoisomerase II [222]. Initial studies in the NCI-60 human cancer cell lines screen suggested that the activity of batracylin was closely related to other topoisomerase II inhibitors [223]. However, study by Rao et al. showed that batracylin exhibited both topoisomerase I- and II-mediated DNA cleavage in vitro and in vivo [224]. The persistence of the topoisomerase/DNA covalent complexes induced by batracylin was significantly longer than by conventional topoisomerase targeting drugs, etoposide or camptothecin. Moreover, the activity of batracylin only partially diminished in topoisomerase I-deficient cells or etoposide-resistant cells confirming that both topoisomerases are targets of this compound [225].

The novel phenazine derivative XR11576 (Figure 1) was developed and described as an inhibitor of both topoisomerases I and II [226]. Further study by Jobson et al. confirmed with several in vitro assays that XR11576 mediated both topoisomerase I- and II-associated covalent complexes [227]. This study also showed that XR11576 was more potent in growth inhibition of human chronic myeloid leukemia cell line K562 than etoposide and camptothecin. Moreover, XR11576 exhibited activity against human colon and small cell lung cancer xenografts and MDR cancer cells that overexpress P-gp and MRP as well as in cells with lower expression of topoisomerase II [228].

\section{MICROTUBULE AND TOPOISOMERASE DUAL INHIBITORS}

MTAs and topoisomerase inhibitors are frequently used in combination for cancer therapy [229]. However, some combinations have antagonistic effects or enhance toxicities [230]. Moreover, the use of MTAs or topoisomerase inhibitors frequently leads to development of drug resistance. Changes in drug binding sites on microtubules or topoisomerases could confer drug resistance by reducing the effective drug binding. Therefore, finding a single agent that inhibits both targets could be beneficial in overcoming drug resistance and enable simpler and easier drug administration.

YCH337 is novel $\alpha$-carboline derivative that targets both microtubule and topoisomerase II [229]. YCH337 inhibits microtubule polymerization by binding to the colchicine binding site, thus disrupting spindle assembly and subsequently leading to mitotic arrest. It also inhibits topoisomerase II and causes DNA double strand breaks. YCH337 induced non-selective growth inhibition in different cancer cell lines originated from 10 different tissues [229]. It also significantly suppressed the growth of human colorectal carcinoma xenografts in mice [229]. YCH337 showed the same efficiency in drug resistant cancer cells, established with either MTAs or topoisomerase II inhibitors, and their sensitive counterparts [229]. This indicates that the existence of resistance mechanisms could not alter YCH337's efficiency. Thus, YCH337 can be considered a novel microtubule and topoisomerase II inhibitor with broad anticancer activity and with potential to overcome drug resistance.

We have also reported a novel dual microtubule and topoisomerase II inhibitor DTA0100 (Figure 1) [231]. Molecular docking study showed that DTA0100 binds at the binding pocket of the topoisomerase II $\alpha$ subunit and act as topoisomerase II catalytic inhibitor [232]. This propargylic enol ether derivative inhibited tubulin polymerization in vitro in the same manner as colchicine. Molecular docking study verified that DTA0100 binds to microtubule at colchicine binding site [231]. DTA0100 efficacy was not significantly changed in MDR cancer cells with the overexpression of P-gp in contrast to other MTAs such as PTX, vinblastine and colchicine. In 
these cells, DTA0100 induced microtubule depolymerization, leading to disturbance of cell cycle kinetics and subsequent apoptosis. Importantly, DTA0100 was able to suppress P-gp activity in MDR cancer cell lines without inducing P-gp expression [231]. Therefore, DTA0100 acting as dual inhibitor of topoisomerase II and microtubule formation could be considered as a new anticancer agent able to overcome problems that emerge in the therapeutic approaches with either topoisomerase II inhibitors or MTAs.

BPROY007 (Figure 1) is a new anticancer agent that inhibits both topoisomerase I and microtubule polymerization [233]. This compound induced topoisomerase I-mediated single strand DNA breaks in a similar manner as camptothecin, but with less potency. BPR0Y007 displaced Hoechst 33342 dye, suggesting that BPR0Y007 binds to DNA at the Hoechst 33342 binding site [233]. Unlike camptothecin, which accumulates cells in S phase of the cell cycle, BPR0Y007 induces cell cycle arrest in G2/M phase [233]. BPR0Y007 also prevented tubulin polymerization in vivo and in vitro in a similar manner as colchicine and vincristine thus resulting as a microtubule depolymerizing agent [233]. The efficacy of BPR0Y007 was not changed in camptothecin-resistant cancer cells with decreased topoisomerase I expression as well as in vincristine-resistant cancer cells with P-gp overexpression [233]. Moreover, BPR0Y007 efficacy was not altered in etoposide-resistant cancer cells with MRP overexpression and decreased topoisomerase II level [233]. Therefore, BPR0Y007 could be considered as a new anticancer agent with the potential to evade and/or overcome drug resistance.

\section{HYBRID COMPOUNDS AS DUAL INHIBITORS}

Great potential of dual and multiple targeting with a single drug in cancer treatment led to the rational development of dual inhibitors designed as hybrid compounds [234].

This approach involves either the merging of structural features of different drugs in a new molecular structure, or the conjugation of two or more potential anticancer pharmacophores through cleavable/non-cleavable linkers, based on the ability of moieties to retain their affinity and activity for biological targets in the newly synthesized molecule. The interest toward multivalent ligand design is rapidly increasing, due to the potential advantages of such bifunctional molecules. Additionally, multivalent molecules are expected to provide pharmacokinetic and pharmacodynamic advantages over the separate administration of the two drug components [235].

However, it should be stressed that the development of successful multifunctional drugs is a very challenging task. A critical aspect for the design of dual molecules is related to the potency of the single components. The most promising and rational design of novel molecules should be the chemical combination of agents that exhibit biological/biochemical activity in a comparable range of concentrations, to avoid that the biological activity of the dual molecule reflects the predominant mechanism of the most potent moiety. Furthermore, a rational design should take into account specific structural features, to allow the chemical flexibility required to retain activity against each putative target. In addition, the potential "druggability" (appropriate molecular size and physicochemical properties) of the dual agents plays a key role for the success of multitarget approaches [235].

Herein, we described highly promising examples of hybrids that showed potential for overcoming drug resistance.

Based on the hypothesis that bifendate scaffold hybridized with chalcone moiety might enhance the P-gp inhibitory effect of bifendate, a series of bifendate-chalcone hybrids were synthesized [236]. The inhibitory effect on P-gp was evaluated using the classical P-gp inhibitor verapamil (VRP) as a positive control. Since an ideal P-gp inhibitor should reverse MDR at nontoxic concentrations, the intrinsic cytotoxicity of the target compounds against parental sensitive 
K562 cells and K562/A02 cells overexpressing P-gp was determined by MTS assay. The most active compound (Figure 2) showed low intrinsic cytotoxicity $\left(\mathrm{IC}_{50}>200 \mu \mathrm{M}\right)$, while increasing rhodamine 123 accumulation in K562/A02 cells more potently than bifendate and VRP. Consequently, the compound displayed high chemosensitizing effect that persisted longer $(>24$ h) than that observed with VRP $(<6 \mathrm{~h})$. In addition, opposite from VRP, this bifendate-chalcone hybrid showed no stimulation on the P-gp ATPase activity, thus indicating that it is not a P-gp substrate. The results suggested that the bifendate-chalcone hybrids might reverse P-gpmediated MDR by inhibiting P-gp efflux function without influencing P-gp expression.

\section{bifendate}

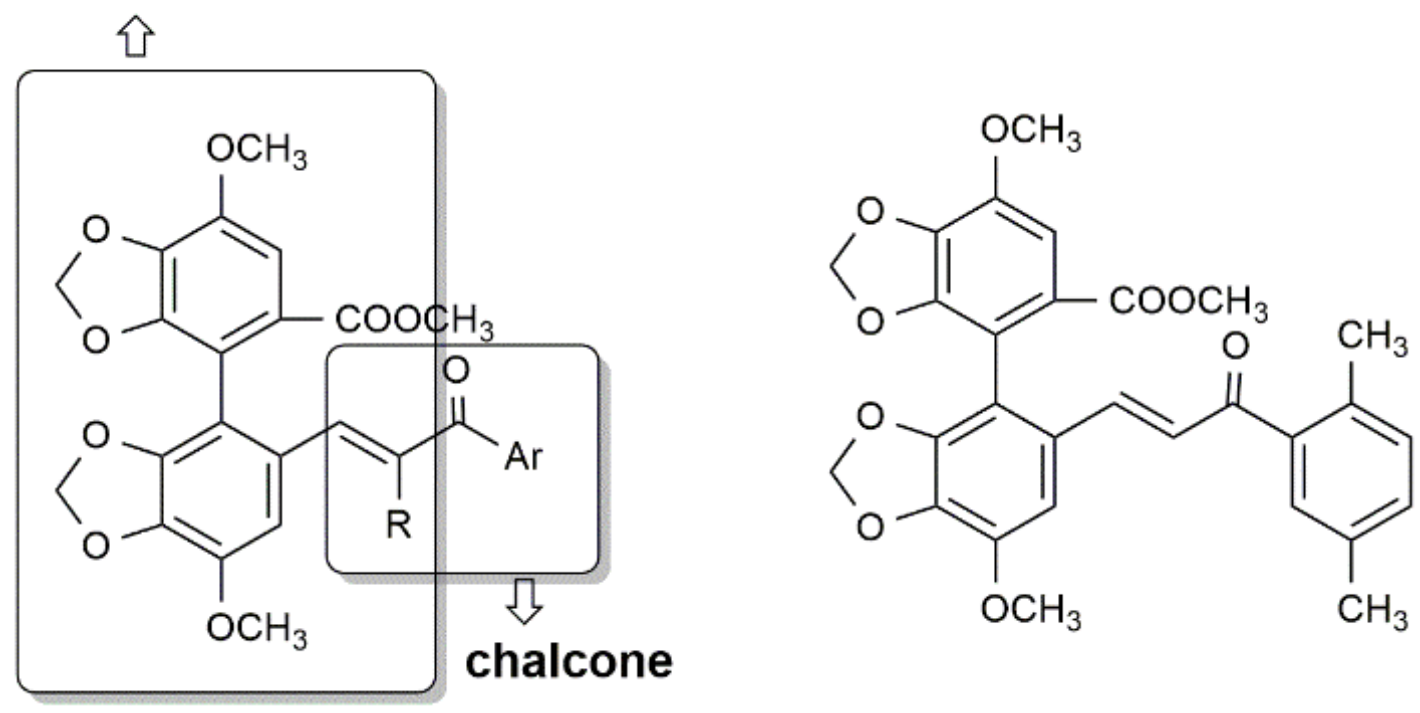

Figure 2. General structure of bifendate-chalcone hybrids and structure of the most active compound against P-gp function.

Hybrid compounds containing a thioxanthone scaffold, known for its anticancer potential, and an amine, considered as an important pharmacophoric feature for P-gp inhibition, were synthesized by Palmeira et al [237]. Docking studies were performed using a dataset of approximately 1000 virtually designed new aminated thioxanthones and two P-gp models constructed using the homologous Sav1866 from Staphylococcus aureus. The molecules with the best docking scores (23 compounds) were then synthesized to perform biological assays. A flow cytometry of rhodamine 123 accumulation assay was performed in order to select the thioxanthones which are able to suppress the efflux of rhodamine 123 by P-gp. Sixteen out of the synthesized compounds induced a significant accumulation of rhodamine 123 after $1 \mathrm{~h}$ of incubation in K562 or K562Dox cell lines showing high potential for P-gp inhibition. The study of the cell growth inhibitory effect of twenty seven thioxanthone in a chronic myelogenous leukemia cell line $\mathrm{K} 562$ showed that six of them have $\mathrm{GI}_{50}$ values below $10 \mathrm{M}$. The best P-gp inhibitor (Figure 3) caused an accumulation rate of rhodamine123 in the K562Dox resistant cell line similar to that caused by VRP. It also induced a decrease in ATP consumption by P-gp. At a concentration of $10 \mu \mathrm{M}$, this compound caused a decrease of 12.5 -fold in the $\mathrm{GI}_{50}$ value for DOX in the K562Dox cell line, being 2-fold more potent than VRP. 

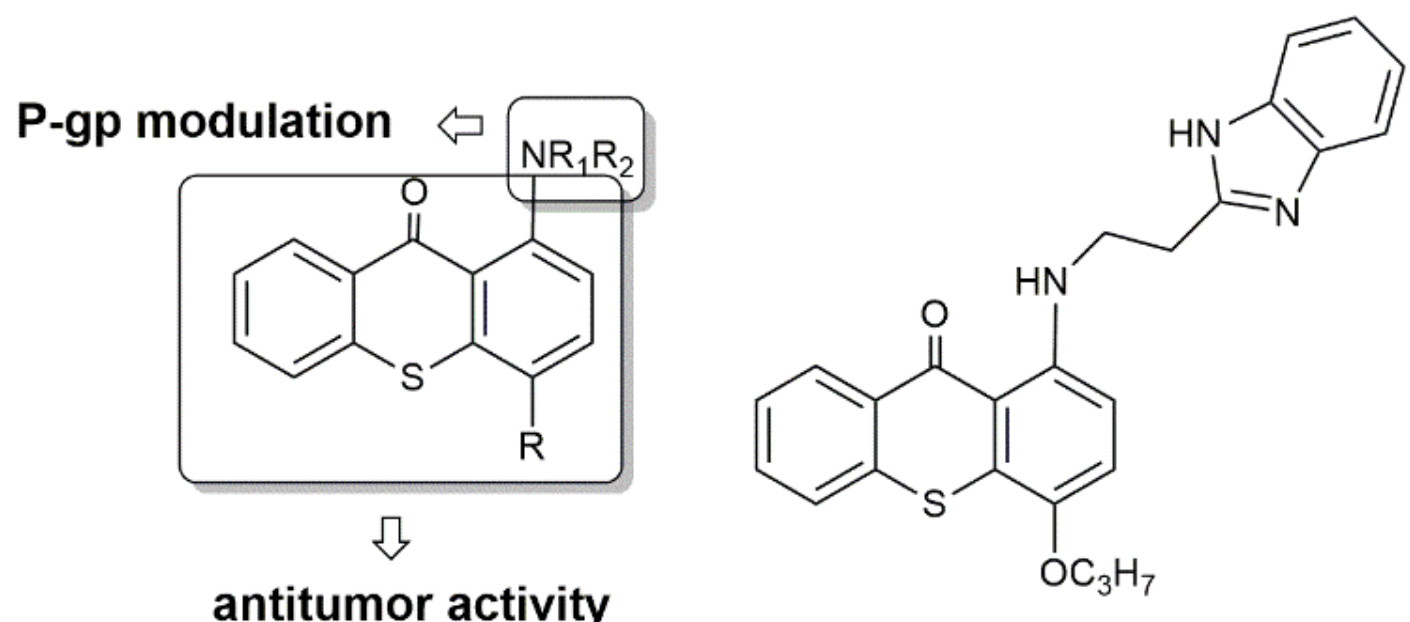

Figure 3. General structure of aminated-thioxantones and structure of the most active compound against P-gp function.

A new series of curcumin-BTP (benzo[b]thiophene 1, 1-dioxide) hybrids were synthesized as STAT3 inhibitors with a potential to produce reactive oxygen species (ROS). The study was performed by Zhang et al. who hypothesized that a combination of STAT3 inhibition and "oxidation therapy" may be a promising strategy to address the MDR issue, due to the important roles of these mechanisms in the cancer cells' survival and development of drug resistance [238]. The most potent compound (Figure 4) exerted potent and selective anticancer activity against MCF-7 and MCF-7/DOX cells ( $\mathrm{IC}_{50}=0.52 \mu \mathrm{M}$ and $0.40 \mu \mathrm{M}$, respectively), with a weak effect on normal MCF-10A breast epithelial cells. Docking studies suggested that this compound might be a STAT3-SH2 domain inhibitor.

Further biological evaluation showed that it inhibited persistent and IL-6-induced STAT3 phosphorylation, nuclear translocation, and DNA binding activity in breast cancer cells.

The compound regulated the expression of the STAT3 downstream genes, Bcl-2, Bax and Cyclin D1, while demonstrated insignificant effect on p-Src or p-Erk.

Interestingly, it also inhibited STAT3-mediated P-gp expression in MCF-7/DOX cells and promoted intracellular ROS production and accumulation. Additionally, it induced cancer cell cycle arrest and apoptosis. Furthermore, this compound significantly reduced the volume of human implanted breast cancer in vivo at a dose of $10 \mathrm{mg} / \mathrm{kg}$ showing low toxicity. 


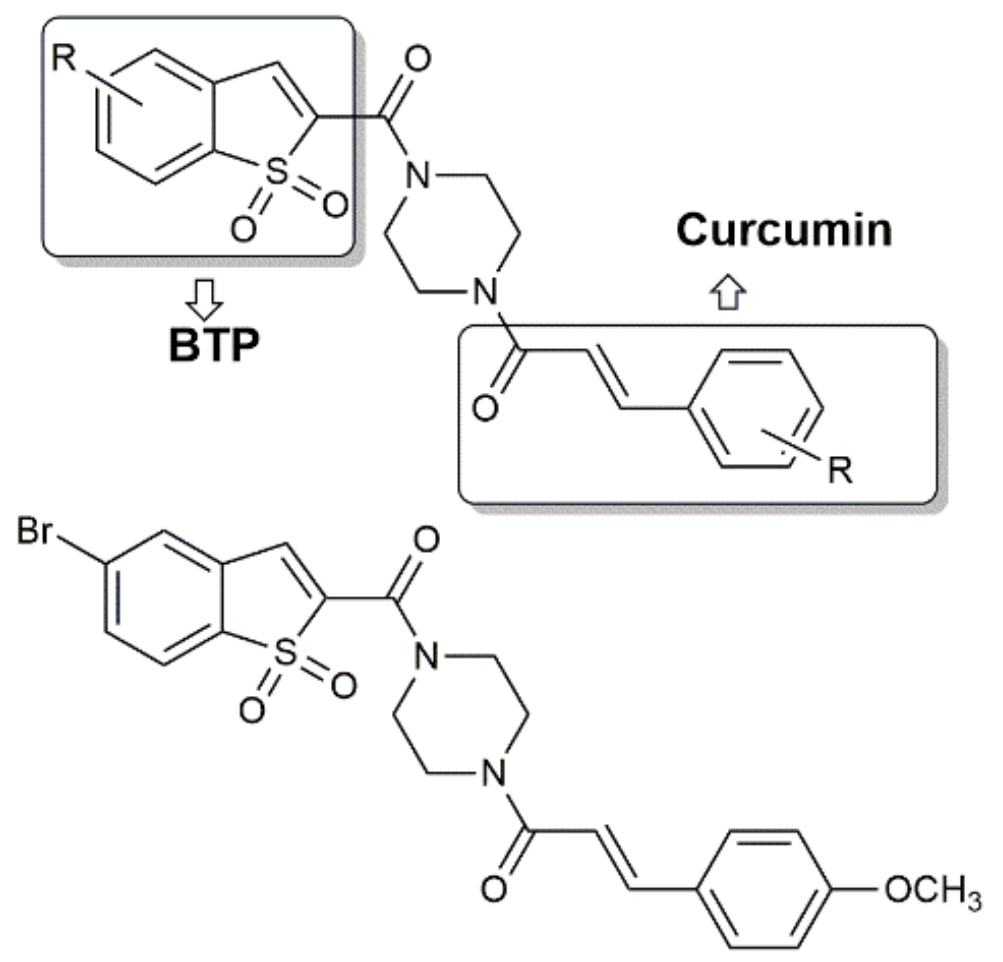

Figure 4. General structure of monocarbonyl curcumin-BTP hybrids and the most active compound against P-gp expression.

$\mathrm{Xu}$ et al. designed a series of novel oridonin-coupled nitrogen mustard conjugates [239].

The hybrids were screened for their in vitro antiproliferative activities against four human cancer cell lines (K562, MCF-7, Bel-7402, and MGC-803) The $\mathrm{IC}_{50}$ values revealed that all the conjugates were more potent than positive control drugs chlorambucil and melphalan. Among them, the most potent hybrid showed $\mathrm{IC}_{50}$ values $0.68 \pm 0.02$ and $0.50 \pm 0.01 \mu \mathrm{M}$ against MCF-7 and Bel-7402 cells, respectively (Figure 5). Interestingly, the compound also exhibited potent antiproliferative activity against MDR cell lines and their sensitive counterparts (SW620, SW620/AD300, NCI-H460, and NCI-H460/MX20 cell lines: IC $_{50}$ values $1.96 \pm 0.11,1.86 \pm$ $0.06,2.35 \pm 0.14$, and $2.91 \pm 0.12 \mu \mathrm{M}$, respectively) [239].

Furthermore, it was found that this compound had an approximately 8 -fold higher selectivity for cancer cells than normal cells, which was higher than selectivity observed with parental compound oridonin and clinically used nitrogen mustard drugs. 


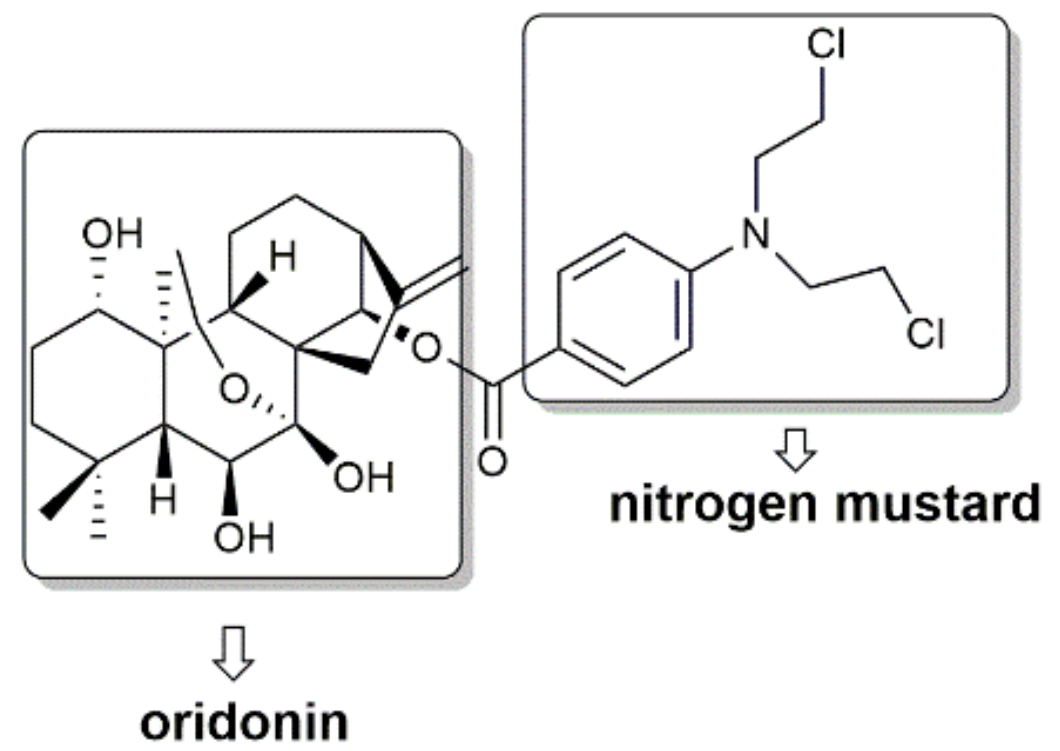

Figure 5. Structure of oridonin-coupled nitrogen mustard conjugate.

Singh and Paul developed nine hybrid molecules having the structural features of 5fluorouracil and the MDR modulator propafenone [240]. The compounds were studied for their interactions with P-gp and evaluated in terms of the change in the basal activity of P-gp (Figure 6). Two compounds exhibited appreciable interactions with P-gp at sub-micromolar concentrations.

The P-gp interacting behavior of these compounds was correlated with some of their physicochemical properties (e.g $\log \mathrm{P}$ and total polar surface area).

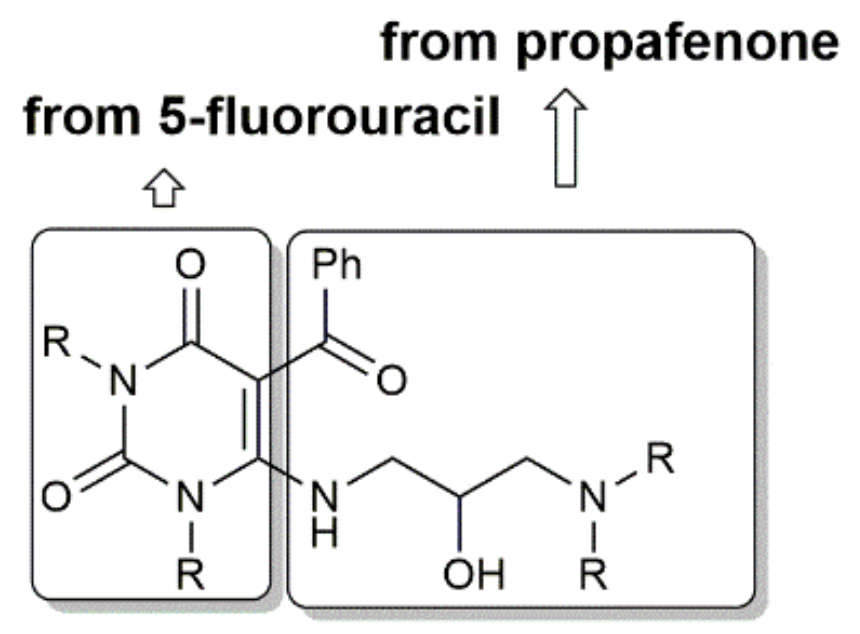

Figure 6. General structure of 5-fluorouracil-propafenone hybrids.

Huang and co-workers hypothesized that conjugates of cytotoxic DNA damaging platinumbased drugs with MTAs could improve the anticancer activity of platinum drugs and overcome their adverse side effects.

Based on the evidence that Pt(IV) complexes, showing kinetic inertness compared with their $\mathrm{Pt}$ (II) counterparts, can be effectively reduced to $\mathrm{Pt}(\mathrm{II})$ equivalents once inside the cells, the authors designed and synthesized three Pt(IV) prodrugs derived cisplatin, oxaliplatin and DACHPt, containing a phenstatin, an inhibitor of tubulin polymerization [241]. 
All resulting $\mathrm{Pt}(\mathrm{IV})$ complexes exhibited better antitumor activities than their $\mathrm{Pt}(\mathrm{II})$ counterparts on a panel of human cancer cell lines including HepG-2, Bel-7404, NCI-H460 and MGC-803. In particular, the $\mathrm{Pt}(\mathrm{IV})$ derivative of cisplatin (Figure 7) exerted better effects against all tested cancer cell lines than cisplatin and synchronously displayed lower cytotoxicity toward NCM460 (human normal colon mucosal epithelial cell line) and HL-7702 (human normal liver cell line).

In addition, hybrid compounds showed significant anticancer activity against cisplatin resistant cell lines. The most potent complex (Figure 7) displayed activity against SK-OV-3 and A549 cancer cell lines showing lower resistance index than cisplatin. Further mechanistic evaluation of this compound revealed that it can effectively enter cells, strongly inhibit tubulin polymerization, arrest the cell cycle at G2/M phases, and markedly enhance the apoptosis. The apoptotic cell death in human NCLC cell line NCI-H460 was induced through the mitochondrial mediated pathway. In vivo studies showed that this hybrid has a potent inhibitory effect on tumor growth in the NCI-H460 xenograft mouse model.
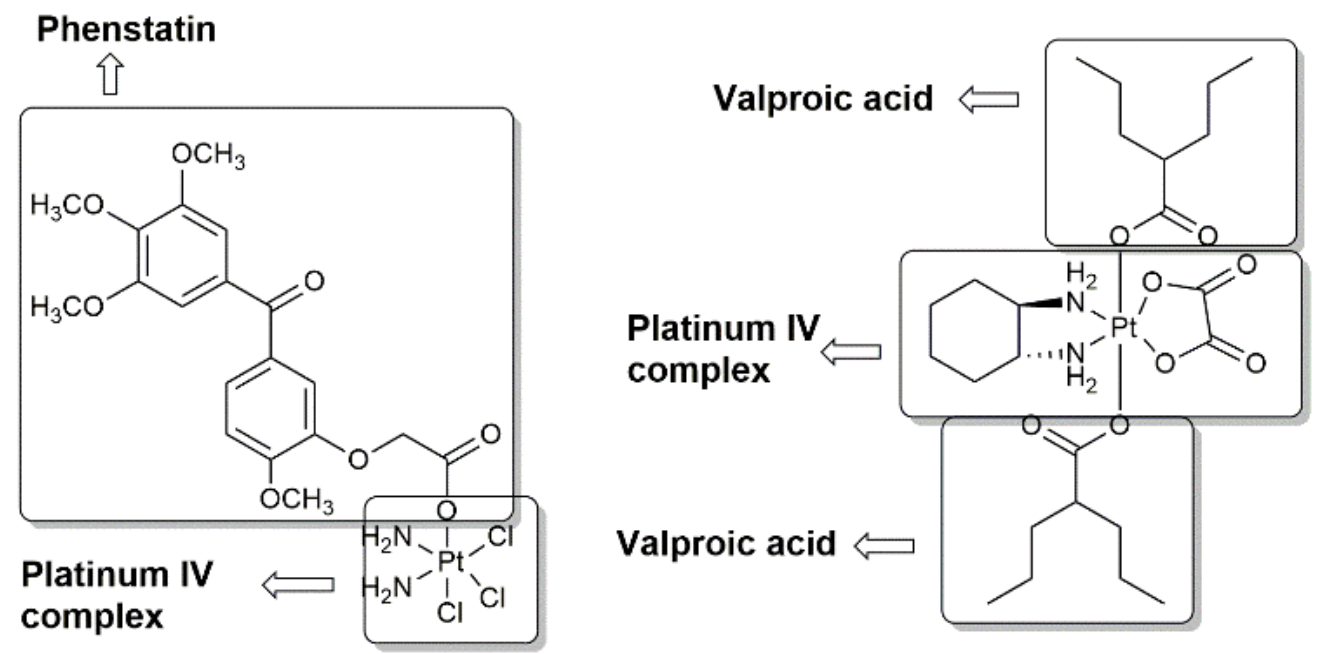

Figure 7. Structures of Platinum(IV) complexes - phenstatin and platinum(IV) complexes - VPA conjugates

Novohradsky et al. prepared Pt(IV) derived prodrugs containing oxaliplatin conjugated with valproic acid (VPA), a well-known drug having histone deacetylase inhibitory activity (Figure 7). The conjugates displayed activity in both cisplatin sensitive and resistant tumor cells, concurrently targeting histone deacetylase and genomic DNA [242].

Other examples of $\mathrm{Pt}(\mathrm{IV})$ based hybrid compounds can be found in a recent review [243].

The widely used combinations of camptothecin (CPT) with platinum compounds exhibit synergism in terms of both efficacy and toxicity. To exploit this synergy in a single compound, Cincinelli and co-workers developed hybrid agents formed by 7-oxyiminomethylcamptothecin derivatives and diaminedichloro-platinum (II) complex. Molecular modelling studies guided the design of the compounds [244].

The derivatives showed growth inhibitory activity against a panel of human cancer cell lines, with potency similar/superior to Topotecan (TPT) and in general superior to cisplatin (cDDP).

The potential advantage of the conjugates was also supported by the reduced resistance indexes observed for CPT-Pt derivatives with respect to cDDP and TPT in several human cancer cell lines (A431/Pt, U2OS/Pt, IGROV-1/Pt, IGROV-1/OHP and A2780/CP). Significantly, the most active derivative (Figure 8) was able to overcome cisplatin resistance in the osteosarcoma U2OS/Pt cell line. 
Drug uptake was evaluated in $\mathrm{H} 460$ cells exposed for $1 \mathrm{~h}$ to equitoxic or equimolar concentrations of compounds. At equitoxic concentrations a marked cellular uptake of hybrid compounds was observed. Interestingly, the uptake of tested hybrid was comparable to that of cDDP, in spite of its 55-fold lower concentration. After exposure to equimolar drug concentration, a significantly higher cellular $\mathrm{Pt}$ accumulation was evidenced for hybrid compounds with respect to cDDP.

Platinum-containing camptothecins produced platinum-DNA adducts and topoisomerase Imediated DNA damage with cleavage pattern and persistence similar to SN38, the active principle of irinotecan. Thus, CPT-Pt hybrids exhibited activity both as Topo I poisons and as DNA-alkylating molecules, indicating that the conjunction of these two components in a single hybrid molecule did not negatively impact on their properties as single drugs.

Results obtained in a cell-free system and in experiments involving yeast cells documented that DNA damage produced by the CPT-Pt molecules was increased in the presence of Topo I, and that the presence of Topo I, but not BSA, produced a dose-dependent accumulation of DNA.

The most active compound (Figure 8) exhibited an appreciable activity in vivo against human H460 tumor xenograft, comparable to that of irinotecan at lower well-tolerated dose levels and superior to cisplatin.

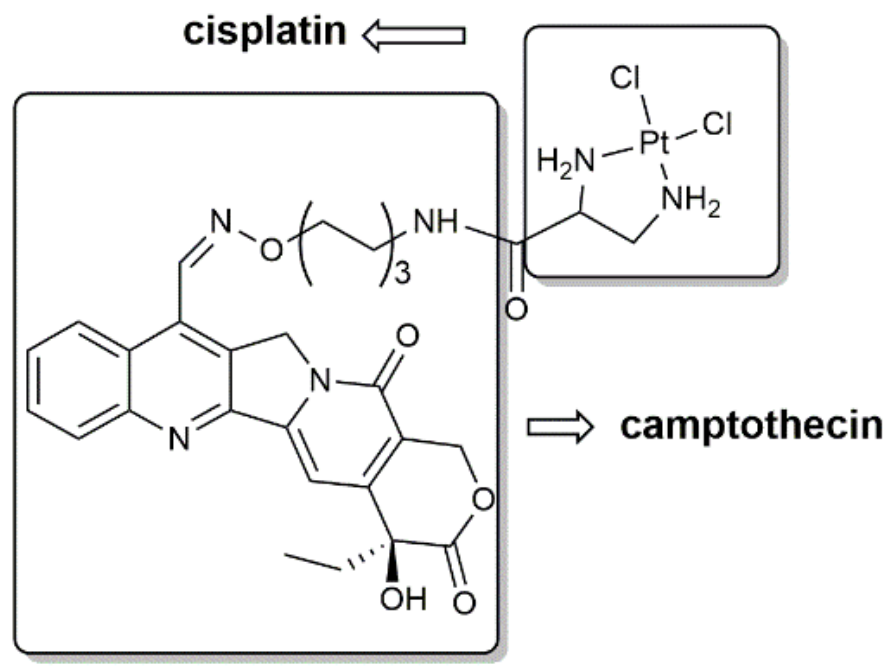

Figure 8. Structure of CPT-cisplatin conjugate

Recent studies have demonstrated enhanced anticancer effects of combination therapy consisting of camptothecin derivatives and HDAC inhibitors. Based on these results, Cincinelli and co-workers have designed dual-acting molecules simultaneously targeting topoisomerase I and HDAC [245].

In particular, substituted (E)-7-oxyminomethyl CPTs were selected for conjugation to a psammaplin A active fragment through an amide bond. The ability of the compounds to act as both HDAC and Topoisomerase-I ligands was studied by molecular modeling and the choice of the spacer length was based on preliminary virtual screening studies.

The most active compound (Figure 9) showed significant antiproliferative activity in a nanomolar range on a series of human solid cancer cell lines, hematologic cancer cell lines and human ex-vivo luciferase-transfected mesothelioma cell lines. The effects were stronger than that obtained with the reference compounds SAHA and irinotecan. 
Interestingly, the efficacy of tested hybrid seemed to be poorly affected by the presence of Pgp, as showed by comparing the $\mathrm{IC}_{50}$ against $\mathrm{A} 2780$ with respect to resistant A2780-Dox cell lines.

In terms of HDACs inhibition, the compound showed a significant activity against four purified HDAC isoforms, representative of class I (HDAC 1, 2) and Class IIb (HDAC 6, 10) HDACs, displaying optimal activity against HDAC10.

The exposure of MM473 cells induced hyperacetylation of nuclear histone H4 protein, the substrate of HDAC1/2, but without hyperacetylation of cytoplasmatic $\alpha$ tubulin, a substrate of HDAC6. This result suggested a preferential nuclear localization that could be relevant for the exploitation of the dual HDAC/Top1 mechanism.

The compound was also tested on MM473 and MM487 cell lines to assess the effect on cell cycle progression and induction of apoptosis. FACS analysis revealed a steady block of treatedcells in S or S-G2M phase. Moreover, an effective induction of apoptosis (sub-G0/1 population) was triggered in both cancer cell lines, with more prominient effect on biphasic MM487 mesotelioma cell line.

In an in vivo human mesothelioma tumor model this hybrid showed a significant antitumor activity and promising tolerability [245].

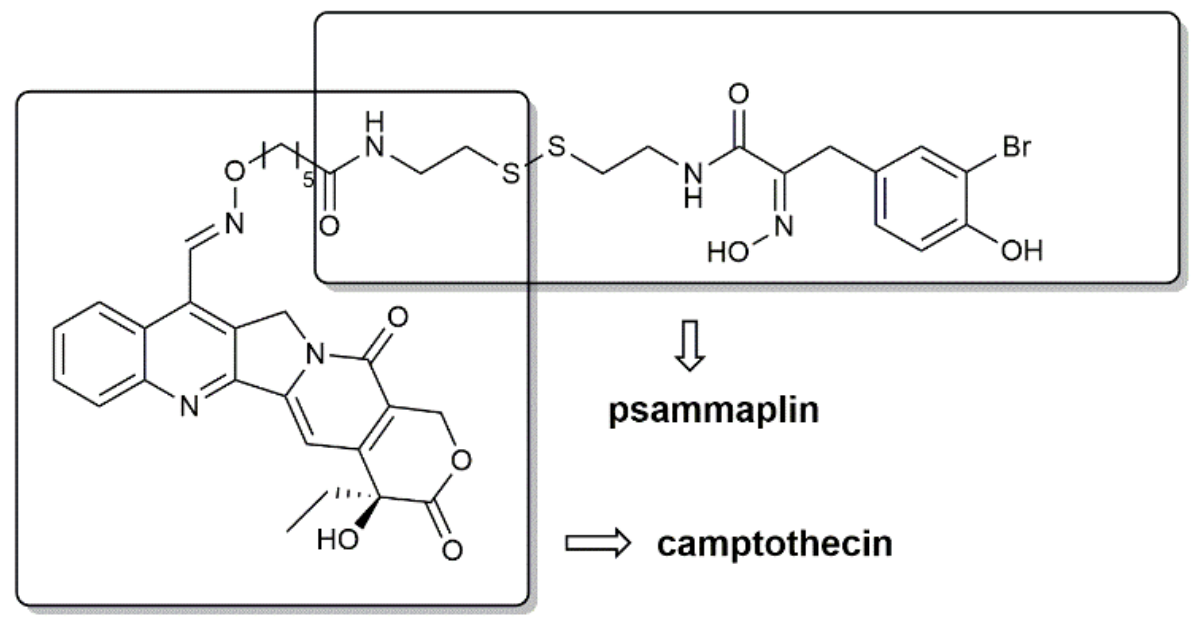

Figure 9. General structure of CPT-psammaplin A hybrids and the most potent compound

\section{CONCLUSION}

Dual-targeting inhibitors evaluated in this review represent several highly promising groups of anticancer agents: TKIs, natural-based compounds, MTAs, topoisomerase inhibitors, and hybrid compounds with the ability to interact with P-gp and suppress its activity. The activity of P-gp, as a transporter with high promiscuity, is intriguing for both normal and pathological conditions. While it has a protective role in normal tissues and organs, its functioning in cancer cells reduces the efficacy of many anticancer drugs. Therefore, recognizing the potential of anticancer compounds to inhibit Pgp function/expression is an important task in the search for more efficient treatment strategies. Some of these agents i.e. TKIs are already in clinical practice, while some of the described compounds are novel and less explored. By giving a comprehensive overview of their anticancer activities, we underlined their key features: inhibition of two or more targets within a cancer cell and capability to evade/overcome MDR, mainly by inhibition of the P-gp function. Other benefits of drugs with multiple targets include better efficacy, enhanced selectivity and tolerability. We believe that 
further development and investigation of abovementioned dual-inhibitors will lead to the necessary optimization of cancer treatment.

\section{CONFLICT OF INTEREST}

The authors declare no conflict of interest.

\section{ACKNOWLEDGEMENTS}

This research was supported by the Ministry of Education, Science and Technological Development of the Republic of Serbia (Grant No III41031). This work was performed within the framework of COST Action CM1106 (Chemical Approaches to Targeting Drug Resistance in Cancer Stem Cells).

\section{REFERENCES}

[1] Raghavendra, N.M.; Pingili, D.; Kadasi, S.; Mettu, A.; Prasad, S.V.U.M., Dual or multitargeting inhibitors: The next generation anticancer agents. European journal of medicinal chemistry, 2018, 143, 1277-1300.

[2] Fu, R.-g.; Sun, Y.; Sheng, W.-b.; Liao, D.-f., Designing multi-targeted agents: An emerging anticancer drug discovery paradigm. European journal of medicinal chemistry, 2017, $136,195-211$.

[3] Wijdeven, R.H.; Pang, B.; Assaraf, Y.G.; Neefjes, J., Old drugs, novel ways out: Drug resistance toward cytotoxic chemotherapeutics. Drug resistance updates : reviews and commentaries in antimicrobial and anticancer chemotherapy, 2016, 28, 65-81.

[4] Palmeira, A.; Sousa, E.; Vasconcelos, M.H.; Pinto, M.M., Three decades of P-gp inhibitors: skimming through several generations and scaffolds. Current medicinal chemistry, 2012, 19, (13), 1946-2025.

[5] Kim, Y.; Chen, J., Molecular structure of human P-glycoprotein in the ATP-bound, outward-facing conformation. Science (New York, N.Y.), 2018, 359, (6378), 915-919.

[6] Li, W.; Zhang, H.; Assaraf, Y.G.; Zhao, K.; Xu, X.; Xie, J.; Yang, D.H.; Chen, Z.S., Overcoming $\mathrm{ABC}$ transporter-mediated multidrug resistance: Molecular mechanisms and novel therapeutic drug strategies. Drug resistance updates : reviews and commentaries in antimicrobial and anticancer chemotherapy, 2016, 27, 14-29.

[7] Aller, S.G.; Yu, J.; Ward, A.; Weng, Y.; Chittaboina, S.; Zhuo, R.; Harrell, P.M.; Trinh, Y.T.; Zhang, Q.; Urbatsch, I.L.; Chang, G., Structure of P-glycoprotein Reveals a Molecular Basis for Poly-Specific Drug Binding. Science (New York, N.Y.), 2009, 323, (5922), 1718-1722.

[8] Hall, M.D.; Handley, M.D.; Gottesman, M.M., Is resistance useless? Multidrug resistance and collateral sensitivity. Trends in pharmacological sciences, 2009, 30, (10), 546-556.

[9] Krause, D.S.; Van Etten, R.A., Tyrosine kinases as targets for cancer therapy. The New England journal of medicine, 2005, 353, (2), 172-187.

[10] Chen, Y.-f.; Fu, L.-w., Mechanisms of acquired resistance to tyrosine kinase inhibitors. Acta Pharmaceutica Sinica B, 2011, 1, (4), 197-207.

[11] Brozik, A.; Hegedus, C.; Erdei, Z.; Hegedus, T.; Ozvegy-Laczka, C.; Szakacs, G.; Sarkadi, B., Tyrosine kinase inhibitors as modulators of ATP binding cassette multidrug transporters: substrates, chemosensitizers or inducers of acquired multidrug resistance? Expert opinion on drug metabolism \& toxicology, 2011, 7, (5), 623-642. 
[12] Beretta, G.L.; Cassinelli, G.; Pennati, M.; Zuco, V.; Gatti, L., Overcoming ABC transporter-mediated multidrug resistance: The dual role of tyrosine kinase inhibitors as multitargeting agents. European journal of medicinal chemistry, 2017, 142, 271-289.

[13] Hegedus, C.; Ozvegy-Laczka, C.; Apati, A.; Magocsi, M.; Nemet, K.; Orfi, L.; Keri, G.; Katona, M.; Takats, Z.; Varadi, A.; Szakacs, G.; Sarkadi, B., Interaction of nilotinib, dasatinib and bosutinib with $\mathrm{ABCB} 1$ and $\mathrm{ABCG} 2$ : implications for altered anti-cancer effects and pharmacological properties. British journal of pharmacology, 2009, 158, (4), 1153-1164.

[14] Xavier, C.P.; Pesic, M.; Vasconcelos, M.H., Understanding Cancer Drug Resistance by Developing and Studying Resistant Cell Line Models. Current cancer drug targets, 2016, 16, (3), 226-237.

[15] Li, Y.H.; Wang, P.P.; Li, X.X.; Yu, C.Y.; Yang, H.; Zhou, J.; Xue, W.W.; Tan, J.; Zhu, F., The Human Kinome Targeted by FDA Approved Multi-Target Drugs and Combination Products: A Comparative Study from the Drug-Target Interaction Network Perspective. PloS one, 2016, 11, (11), e0165737.

[16] Shukla, S.; Sauna, Z.E.; Ambudkar, S.V., Evidence for the interaction of imatinib at the transport-substrate site(s) of the multidrug-resistance-linked ABC drug transporters ABCB1 (Pglycoprotein) and ABCG2. Leukemia, 2008, 22, (2), 445-447.

[17] Chen, B.A.; Shan, X.Y.; Chen, J.; Xia, G.H.; Xu, W.L.; Schmit, M., Effects of imatinib and 5-bromotetrandrine on the reversal of multidrug resistance of the K562/A02 cell line. Chinese journal of cancer, 2010, 29, (6), 591-595.

[18] Dohse, M.; Scharenberg, C.; Shukla, S.; Robey, R.W.; Volkmann, T.; Deeken, J.F.; Brendel, C.; Ambudkar, S.V.; Neubauer, A.; Bates, S.E., Comparison of ATP-binding cassette transporter interactions with the tyrosine kinase inhibitors imatinib, nilotinib, and dasatinib. Drug metabolism and disposition: the biological fate of chemicals, 2010, 38, (8), 1371-1380.

[19] Mukai, M.; Che, X.F.; Furukawa, T.; Sumizawa, T.; Aoki, S.; Ren, X.Q.; Haraguchi, M.; Sugimoto, Y.; Kobayashi, M.; Takamatsu, H.; Akiyama, S., Reversal of the resistance to STI571 in human chronic myelogenous leukemia K562 cells. Cancer science, 2003, 94, (6), 557-563.

[20] Sims, J.T.; Ganguly, S.S.; Bennett, H.; Friend, J.W.; Tepe, J.; Plattner, R., Imatinib reverses doxorubicin resistance by affecting activation of STAT3-dependent NF-kappaB and HSP27/p38/AKT pathways and by inhibiting ABCB1. PloS one, 2013, 8, (1), e55509.

[21] Mlejnek, P.; Kosztyu, P.; Dolezel, P.; Bates, S.E.; Ruzickova, E., Reversal of ABCB1 mediated efflux by imatinib and nilotinib in cells expressing various transporter levels. Chemicobiological interactions, 2017, 273, 171-179.

[22] Yeheskely-Hayon, D.; Regev, R.; Eytan, G.D.; Dann, E.J., The tyrosine kinase inhibitors imatinib and AG957 reverse multidrug resistance in a chronic myelogenous leukemia cell line. Leukemia research, 2005, 29, (7), 793-802.

[23] Husaini, R.; Ahmad, M.; Zakaria, Z., Effectiveness of imatinib mesylate over etoposide in the treatment of sensitive and resistant chronic myeloid leukaemia cells in vitro. Experimental and therapeutic medicine, 2017, 13, (6), 3209-3216.

[24] Negi, L.M.; Jaggi, M.; Joshi, V.; Ronodip, K.; Talegaonkar, S., Hyaluronan coated liposomes as the intravenous platform for delivery of imatinib mesylate in MDR colon cancer. International journal of biological macromolecules, 2015, 73, 222-235.

[25] Villar, V.H.; Vogler, O.; Martinez-Serra, J.; Ramos, R.; Calabuig-Farinas, S.; Gutierrez, A.; Barcelo, F.; Martin-Broto, J.; Alemany, R., Nilotinib counteracts P-glycoprotein-mediated multidrug resistance and synergizes the antitumoral effect of doxorubicin in soft tissue sarcomas. PloS one, 2012, 7, (5), e37735.

[26] Tiwari, A.K.; Sodani, K.; Wang, S.R.; Kuang, Y.H.; Ashby, C.R., Jr.; Chen, X.; Chen, Z.S., Nilotinib (AMN107, Tasigna) reverses multidrug resistance by inhibiting the activity of the ABCB1/Pgp and ABCG2/BCRP/MXR transporters. Biochemical pharmacology, 2009, 78, (2), 153-161. 
[27] Wang, F.; Wang, X.K.; Shi, C.J.; Zhang, H.; Hu, Y.P.; Chen, Y.F.; Fu, L.W., Nilotinib enhances the efficacy of conventional chemotherapeutic drugs in CD34(+)CD38(-) stem cells and ABC transporter overexpressing leukemia cells. Molecules (Basel, Switzerland), 2014, 19, (3), 3356-3375.

[28] Zhou, Z.Y.; Wan, L.L.; Yang, Q.J.; Han, Y.L.; Li, D.; Lu, J.; Guo, C., Nilotinib reverses ABCB1/P-glycoprotein-mediated multidrug resistance but increases cardiotoxicity of doxorubicin in a MDR xenograft model. Toxicology letters, 2016, 259, 124-132.

[29] Tiwari, A.K.; Sodani, K.; Dai, C.L.; Abuznait, A.H.; Singh, S.; Xiao, Z.J.; Patel, A.; Talele, T.T.; Fu, L.; Kaddoumi, A.; Gallo, J.M.; Chen, Z.S., Nilotinib potentiates anticancer drug sensitivity in murine ABCB1-, ABCG2-, and ABCC10-multidrug resistance xenograft models. Cancer letters, 2013, 328, (2), 307-317.

[30] Chen, T.; Wang, C.; Liu, Q.; Meng, Q.; Sun, H.; Huo, X.; Sun, P.; Peng, J.; Liu, Z.; Yang, X.; Liu, K., Dasatinib reverses the multidrug resistance of breast cancer MCF-7 cells to doxorubicin by downregulating P-gp expression via inhibiting the activation of ERK signaling pathway. Cancer biology \& therapy, 2015, 16, (1), 106-114.

[31] Li, J.; Xu, R.; Lu, X.; He, J.; Jin, S., A simple reduction-sensitive micelles co-delivery of paclitaxel and dasatinib to overcome tumor multidrug resistance. International journal of nanomedicine, 2017, 12, 8043-8056.

[32] Tsubaki, M.; Komai, M.; Itoh, T.; Imano, M.; Sakamoto, K.; Shimaoka, H.; Takeda, T.; Ogawa, N.; Mashimo, K.; Fujiwara, D.; Mukai, J.; Sakaguchi, K.; Satou, T.; Nishida, S., By inhibiting Src, verapamil and dasatinib overcome multidrug resistance via increased expression of Bim and decreased expressions of MDR1 and survivin in human multidrug-resistant myeloma cells. Leukemia research, 2014, 38, (1), 121-130.

[33] Sen, R.; Natarajan, K.; Bhullar, J.; Shukla, S.; Fang, H.B.; Cai, L.; Chen, Z.S.; Ambudkar, S.V.; Baer, M.R., The novel BCR-ABL and FLT3 inhibitor ponatinib is a potent inhibitor of the MDR-associated ATP-binding cassette transporter ABCG2. Molecular cancer therapeutics, 2012, 11, (9), 2033-2044.

[34] Yang, C.H.; Huang, C.J.; Yang, C.S.; Chu, Y.C.; Cheng, A.L.; Whang-Peng, J.; Yang, P.C., Gefitinib reverses chemotherapy resistance in gefitinib-insensitive multidrug resistant cancer cells expressing ATP-binding cassette family protein. Cancer research, 2005, 65, (15), 6943-6949.

[35] Kitazaki, T.; Oka, M.; Nakamura, Y.; Tsurutani, J.; Doi, S.; Yasunaga, M.; Takemura, M.; Yabuuchi, H.; Soda, H.; Kohno, S., Gefitinib, an EGFR tyrosine kinase inhibitor, directly inhibits the function of P-glycoprotein in multidrug resistant cancer cells. Lung cancer, 2005, 49, (3), 337-343.

[36] Leggas, M.; Panetta, J.C.; Zhuang, Y.; Schuetz, J.D.; Johnston, B.; Bai, F.; Sorrentino, B.; Zhou, S.; Houghton, P.J.; Stewart, C.F., Gefitinib modulates the function of multiple ATPbinding cassette transporters in vivo. Cancer research, 2006, 66, (9), 4802-4807.

[37] Wang, Y.J.; Zhang, Y.K.; Zhang, G.N.; Al Rihani, S.B.; Wei, M.N.; Gupta, P.; Zhang, X.Y.; Shukla, S.; Ambudkar, S.V.; Kaddoumi, A.; Shi, Z.; Chen, Z.S., Regorafenib overcomes chemotherapeutic multidrug resistance mediated by ABCB1 transporter in colorectal cancer: In vitro and in vivo study. Cancer letters, 2017, 396, 145-154.

[38] Inoue, Y.; Ikegami, Y.; Sano, K.; Suzuki, T.; Yoshida, H.; Nakamura, Y.; Nakagawa, H.; Ishikawa, T., Gefitinib enhances the antitumor activity of CPT-11 in vitro and in vivo by inhibiting $\mathrm{ABCG} 2$ but not $\mathrm{ABCB} 1$ : a new clue to circumvent gastrointestinal toxicity risk. Chemotherapy, 2013, 59, (4), 260-272.

[39] Azzariti, A.; Porcelli, L.; Simone, G.M.; Quatrale, A.E.; Colabufo, N.A.; Berardi, F.; Perrone, R.; Zucchetti, M.; D'Incalci, M.; Xu, J.M.; Paradiso, A., Tyrosine kinase inhibitors and multidrug resistance proteins: interactions and biological consequences. Cancer chemotherapy and pharmacology, 2010, 65, (2), 335-346. 
[40] Wang, W.J.; Li, C.F.; Chu, Y.Y.; Wang, Y.H.; Hour, T.C.; Yen, C.J.; Chang, W.C.; Wang, J.M., Inhibition of the EGFR/STAT3/CEBPD Axis Reverses Cisplatin Cross-resistance with Paclitaxel in the Urothelial Carcinoma of the Urinary Bladder. Clinical cancer research : an official journal of the American Association for Cancer Research, 2017, 23, (2), 503-513.

[41] Shi, Z.; Peng, X.X.; Kim, I.W.; Shukla, S.; Si, Q.S.; Robey, R.W.; Bates, S.E.; Shen, T.; Ashby, C.R., Jr.; Fu, L.W.; Ambudkar, S.V.; Chen, Z.S., Erlotinib (Tarceva, OSI-774) antagonizes ATP-binding cassette subfamily B member 1 and ATP-binding cassette subfamily G member 2-mediated drug resistance. Cancer research, 2007, 67, (22), 11012-11020.

[42] Lainey, E.; Sebert, M.; Thepot, S.; Scoazec, M.; Bouteloup, C.; Leroy, C.; De Botton, S.; Galluzzi, L.; Fenaux, P.; Kroemer, G., Erlotinib antagonizes ABC transporters in acute myeloid leukemia. Cell cycle, 2012, 11, (21), 4079-4092.

[43] Noguchi, K.; Kawahara, H.; Kaji, A.; Katayama, K.; Mitsuhashi, J.; Sugimoto, Y., Substrate-dependent bidirectional modulation of P-glycoprotein-mediated drug resistance by erlotinib. Cancer science, 2009, 100, (9), 1701-1707.

[44] Wang, X.K.; To, K.K.; Huang, L.Y.; Xu, J.H.; Yang, K.; Wang, F.; Huang, Z.C.; Ye, S.; $\mathrm{Fu}, \mathrm{L} . \mathrm{W}$., Afatinib circumvents multidrug resistance via dually inhibiting ATP binding cassette subfamily G member 2 in vitro and in vivo. Oncotarget, 2014, 5, (23), 11971-11985.

[45] Wang, S.Q.; Liu, S.T.; Zhao, B.X.; Yang, F.H.; Wang, Y.T.; Liang, Q.Y.; Sun, Y.B.; Liu, Y.; Song, Z.H.; Cai, Y.; Li, G.F., Afatinib reverses multidrug resistance in ovarian cancer via dually inhibiting ATP binding cassette subfamily B member 1. Oncotarget, 2015, 6, (28), 2614226160.

[46] Zhang, Y.; Wang, C.Y.; Duan, Y.J.; Huo, X.K.; Meng, Q.; Liu, Z.H.; Sun, H.J.; Ma, X.D.; Liu, K.X., Afatinib Decreases P-Glycoprotein Expression to Promote Adriamycin Toxicity of A549T Cells. Journal of cellular biochemistry, 2018, 119, (1), 414-423.

[47] Liu, H.; Ma, Z.; Wu, B., Structure-activity relationships and in silico models of Pglycoprotein (ABCB1) inhibitors. Xenobiotica; the fate of foreign compounds in biological systems, 2013, 43, (11), 1018-1026.

[48] Gandhi, Y.A.; Morris, M.E., Structure-activity relationships and quantitative structureactivity relationships for breast cancer resistance protein (ABCG2). The AAPS journal, 2009, 11, (3), 541-552.

[49] Zhao, X.Q.; Xie, J.D.; Chen, X.G.; Sim, H.M.; Zhang, X.; Liang, Y.J.; Singh, S.; Talele, T.T.; Sun, Y.; Ambudkar, S.V.; Chen, Z.S.; Fu, L.W., Neratinib reverses ATP-binding cassette B1-mediated chemotherapeutic drug resistance in vitro, in vivo, and ex vivo. Molecular pharmacology, 2012, 82, (1), 47-58.

[50] Collins, D.M.; Crown, J.; O'Donovan, N.; Devery, A.; O'Sullivan, F.; O'Driscoll, L.; Clynes, M.; O'Connor, R., Tyrosine kinase inhibitors potentiate the cytotoxicity of MDRsubstrate anticancer agents independent of growth factor receptor status in lung cancer cell lines. Investigational new drugs, 2010, 28, (4), 433-444.

[51] Dai, C.L.; Tiwari, A.K.; Wu, C.P.; Su, X.D.; Wang, S.R.; Liu, D.G.; Ashby, C.R., Jr.; Huang, Y.; Robey, R.W.; Liang, Y.J.; Chen, L.M.; Shi, C.J.; Ambudkar, S.V.; Chen, Z.S.; Fu, L.W., Lapatinib (Tykerb, GW572016) reverses multidrug resistance in cancer cells by inhibiting the activity of ATP-binding cassette subfamily B member 1 and $\mathrm{G}$ member 2. Cancer research, 2008, 68, (19), 7905-7914.

[52] Dunne, G.; Breen, L.; Collins, D.M.; Roche, S.; Clynes, M.; O'Connor, R., Modulation of P-gp expression by lapatinib. Investigational new drugs, 2011, 29, (6), 1284-1293.

[53] Minami, T.; Kijima, T.; Otani, Y.; Kohmo, S.; Takahashi, R.; Nagatomo, I.; Hirata, H.; Suzuki, M.; Inoue, K.; Takeda, Y.; Kida, H.; Tachibana, I.; Kumanogoh, A., HER2 as therapeutic target for overcoming ATP-binding cassette transporter-mediated chemoresistance in small cell lung cancer. Molecular cancer therapeutics, 2012, 11, (4), 830-841. 
[54] Li, F.; Danquah, M.; Singh, S.; Wu, H.; Mahato, R.I., Paclitaxel- and lapatinib-loaded lipopolymer micelles overcome multidrug resistance in prostate cancer. Drug delivery and translational research, 2011, 1, (6), 420-428.

[55] Dai, C.; Ma, S.; Wang, F.; Zhao, H.; Wu, X.; Huang, Z.; Chen, Z.; To, K.; Fu, L., Lapatinib promotes the incidence of hepatotoxicity by increasing chemotherapeutic agent accumulation in hepatocytes. Oncotarget, 2015, 6, (19), 17738-17752.

[56] Hsiao, S.H.; Lu, Y.J.; Li, Y.Q.; Huang, Y.H.; Hsieh, C.H.; Wu, C.P., Osimertinib (AZD9291) Attenuates the Function of Multidrug Resistance-Linked ATP-Binding Cassette Transporter ABCB1 in Vitro. Molecular pharmaceutics, 2016, 13, (6), 2117-2125.

[57] Chen, Z.; Chen, Y.; Xu, M.; Chen, L.; Zhang, X.; To, K.K.; Zhao, H.; Wang, F.; Xia, Z.; Chen, X.; Fu, L., Osimertinib (AZD9291) Enhanced the Efficacy of Chemotherapeutic Agents in ABCB1- and ABCG2-Overexpressing Cells In Vitro, In Vivo, and Ex Vivo. Molecular cancer therapeutics, 2016, 15, (8), 1845-1858.

[58] Zhang, X.Y.; Zhang, Y.K.; Wang, Y.J.; Gupta, P.; Zeng, L.; Xu, M.; Wang, X.Q.; Yang, D.H.; Chen, Z.S., Osimertinib (AZD9291), a Mutant-Selective EGFR Inhibitor, Reverses ABCB1-Mediated Drug Resistance in Cancer Cells. Molecules (Basel, Switzerland), 2016, 21, (9), 1236.

[59] Chen, S.; Wang, Y.; Ruan, W.; Wang, X.; Pan, C., Reversing multidrug resistance in hepatocellular carcinoma cells by inhibiting extracellular signal-regulated kinase/mitogenactivated protein kinase signaling pathway activity. Oncology letters, 2014, 8, (5), 2333-2339.

[60] Huang, Y.S.; Xue, Z.; Zhang, H., Sorafenib reverses resistance of gastric cancer to treatment by cisplatin through down-regulating MDR1 expression. Medical oncology, 2015, 32, (2), 470.

[61] Hoffmann, K.; Franz, C.; Xiao, Z.; Mohr, E.; Serba, S.; Buchler, M.W.; Schemmer, P., Sorafenib modulates the gene expression of multi-drug resistance mediating ATP-binding cassette proteins in experimental hepatocellular carcinoma. Anticancer research, 2010, 30, (11), 4503-4508.

[62] Eum, K.H.; Ahn, S.K.; Kang, H.; Lee, M., Differential inhibitory effects of two Raftargeting drugs, sorafenib and PLX4720, on the growth of multidrug-resistant cells. Molecular and cellular biochemistry, 2013, 372, (1-2), 65-74.

[63] Hu, S.; Chen, Z.; Franke, R.; Orwick, S.; Zhao, M.; Rudek, M.A.; Sparreboom, A.; Baker, S.D., Interaction of the multikinase inhibitors sorafenib and sunitinib with solute carriers and ATP-binding cassette transporters. Clinical cancer research : an official journal of the American Association for Cancer Research, 2009, 15, (19), 6062-6069.

[64] Wei, Y.; Ma, Y.; Zhao, Q.; Ren, Z.; Li, Y.; Hou, T.; Peng, H., New use for an old drug: inhibiting ABCG2 with sorafenib. Molecular cancer therapeutics, 2012, 11, (8), 1693-1702.

[65] Dai, C.-1.; Liang, Y.-j.; Wang, Y.-s.; Tiwari, A.K.; Yan, Y.-y.; Wang, F.; Chen, Z.-s.; Tong, X.-Z.; Fu, L.-w., Sensitization of ABCG2-overexpressing cells to conventional chemotherapeutic agent by sunitinib was associated with inhibiting the function of ABCG2. Cancer letters, 2009, 279, (1), 74-83.

[66] Shukla, S.; Robey, R.W.; Bates, S.E.; Ambudkar, S.V., Sunitinib (Sutent, SU11248), a small-molecule receptor tyrosine kinase inhibitor, blocks function of the ATP-binding cassette (ABC) transporters P-glycoprotein (ABCB1) and ABCG2. Drug metabolism and disposition: the biological fate of chemicals, 2009, 37, (2), 359-365.

[67] Zhang, Y.; Wang, Q., Sunitinib reverse multidrug resistance in gastric cancer cells by modulating Stat3 and inhibiting P-gp function. Cell biochemistry and biophysics, 2013, 67, (2), $575-581$.

[68] Zhang, K.; Wang, X.; Wang, H., Effect and mechanism of Src tyrosine kinase inhibitor sunitinib on the drug-resistance reversal of human A549/DDP cisplatin-resistant lung cancer cell line. Molecular medicine reports, 2014, 10, (4), 2065-2072. 
[69] Bani, M.; Decio, A.; Giavazzi, R.; Ghilardi, C., Contribution of tumor endothelial cells to drug resistance: anti-angiogenic tyrosine kinase inhibitors act as p-glycoprotein antagonists. Angiogenesis, 2017, 20, (2), 233-241.

[70] Mi, Y.; Lou, L., ZD6474 reverses multidrug resistance by directly inhibiting the function of P-glycoprotein. British journal of cancer, 2007, 97, (7), 934-940.

[71] Jovelet, C.; Benard, J.; Forestier, F.; Farinotti, R.; Bidart, J.M.; Gil, S., Inhibition of Pglycoprotein functionality by vandetanib may reverse cancer cell resistance to doxorubicin. European journal of pharmaceutical sciences : official journal of the European Federation for Pharmaceutical Sciences, 2012, 46, (5), 484-491.

[72] Xiang, Q.F.; Zhang, D.M.; Wang, J.N.; Zhang, H.W.; Zheng, Z.Y.; Yu, D.C.; Li, Y.J.; Xu, J.; Chen, Y.J.; Shang, C.Z., Cabozantinib reverses multidrug resistance of human hepatoma HepG2/adr cells by modulating the function of P-glycoprotein. Liver international : official journal of the International Association for the Study of the Liver, 2015, 35, (3), 1010-1023.

[73] Zhang, G.N.; Zhang, Y.K.; Wang, Y.J.; Barbuti, A.M.; Zhu, X.J.; Yu, X.Y.; Wen, A.W.; Wurpel, J.N.D.; Chen, Z.S., Modulating the function of ATP-binding cassette subfamily G member 2 (ABCG2) with inhibitor cabozantinib. Pharmacological research, 2017, 119, 89-98.

[74] Xiang, Q.F.; Wang, F.; Su, X.D.; Liang, Y.J.; Zheng, L.S.; Mi, Y.J.; Chen, W.Q.; Fu, L.W., Effect of BIBF 1120 on reversal of ABCB1-mediated multidrug resistance. Cellular oncology, 2011, 34, (1), 33-44.

[75] Zhou, W.J.; Zhang, X.; Cheng, C.; Wang, F.; Wang, X.K.; Liang, Y.J.; To, K.K.; Zhou, W.; Huang, H.B.; Fu, L.W., Crizotinib (PF-02341066) reverses multidrug resistance in cancer cells by inhibiting the function of P-glycoprotein. British journal of pharmacology, 2012, 166, (5), 1669-1683.

[76] Hu, J.; Zhang, X.; Wang, F.; Wang, X.; Yang, K.; Xu, M.; To, K.K.; Li, Q.; Fu, L., Effect of ceritinib (LDK378) on enhancement of chemotherapeutic agents in ABCB1 and ABCG2 overexpressing cells in vitro and in vivo. Oncotarget, 2015, 6, (42), 44643-44659.

[77] Yang, K.; Chen, Y.; To, K.K.; Wang, F.; Li, D.; Chen, L.; Fu, L., Alectinib (CH5424802) antagonizes $\mathrm{ABCB} 1$ - and $\mathrm{ABCG} 2-$ mediated multidrug resistance in vitro, in vivo and ex vivo. Experimental \& molecular medicine, 2017, 49, (3), e303.

[78] Gao, Y.; Shen, J.; Choy, E.; Mankin, H.; Hornicek, F.; Duan, Z., Inhibition of CDK4 sensitizes multidrug resistant ovarian cancer cells to paclitaxel by increasing apoptosiss. Cellular oncology, 2017, 40, (3), 209-218.

[79] Wu, T.; Chen, Z.; To, K.K.W.; Fang, X.; Wang, F.; Cheng, B.; Fu, L., Effect of abemaciclib (LY2835219) on enhancement of chemotherapeutic agents in ABCB1 and ABCG2 overexpressing cells in vitro and in vivo. Biochemical pharmacology, 2017, 124, 29-42.

[80] Michaelis, M.; Rothweiler, F.; Nerreter, T.; Van Rikxoort, M.; Sharifi, M.; Wiese, M.; Ghafourian, T.; Cinatl, J., Differential effects of the oncogenic BRAF inhibitor PLX4032 (vemurafenib) and its progenitor PLX4720 on ABCB1 function. Journal of pharmacy \& pharmaceutical sciences : a publication of the Canadian Society for Pharmaceutical Sciences, Societe canadienne des sciences pharmaceutiques, 2014, 17, (1), 154-168.

[81] Qiu, J.G.; Zhang, Y.J.; Li, Y.; Zhao, J.M.; Zhang, W.J.; Jiang, Q.W.; Mei, X.L.; Xue, Y.Q.; Qin, W.M.; Yang, Y.; Zheng, D.W.; Chen, Y.; Wei, M.N.; Shi, Z., Trametinib modulates cancer multidrug resistance by targeting ABCB1 transporter. Oncotarget, 2015, 6, (17), 1549415509.

[82] Zhang, H.; Patel, A.; Wang, Y.J.; Zhang, Y.K.; Kathawala, R.J.; Qiu, L.H.; Patel, B.A.; Huang, L.H.; Shukla, S.; Yang, D.H.; Ambudkar, S.V.; Fu, L.W.; Chen, Z.S., The BTK Inhibitor Ibrutinib (PCI-32765) Overcomes Paclitaxel Resistance in ABCB1- and ABCC10Overexpressing Cells and Tumors. Molecular cancer therapeutics, 2017, 16, (6), 1021-1030.

[83] Podolski-Renic, A.; Jadranin, M.; Stankovic, T.; Bankovic, J.; Stojkovic, S.; Chiourea, M.; Aljancic, I.; Vajs, V.; Tesevic, V.; Ruzdijic, S.; Gagos, S.; Tanic, N.; Pesic, M., Molecular 
and cytogenetic changes in multi-drug resistant cancer cells and their influence on new compounds testing. Cancer chemotherapy and pharmacology, 2013, 72, (3), 683-697.

[84] Milosevic, Z.; Pesic, M.; Stankovic, T.; Dinic, J.; Milovanovic, Z.; Stojsic, J.; Dzodic, R.; Tanic, N.; Bankovic, J., Targeting RAS-MAPK-ERK and PI3K-AKT-mTOR signal transduction pathways to chemosensitize anaplastic thyroid carcinoma. Translational research : the journal of laboratory and clinical medicine, 2014, 164, (5), 411-423.

[85] Mori, M.; Vignaroli, G.; Cau, Y.; Dinic, J.; Hill, R.; Rossi, M.; Colecchia, D.; Pesic, M.; Link, W.; Chiariello, M.; Ottmann, C.; Botta, M., Discovery of 14-3-3 protein-protein interaction inhibitors that sensitize multidrug-resistant cancer cells to doxorubicin and the Akt inhibitor GSK690693. ChemMedChem, 2014, 9, (5), 973-983.

[86] Dragoj, M.; Milosevic, Z.; Bankovic, J.; Tanic, N.; Pesic, M.; Stankovic, T., Targeting CXCR4 and FAK reverses doxorubicin resistance and suppresses invasion in non-small cell lung carcinoma. Cellular oncology, 2017, 40, (1), 47-62.

[87] Abdallah, H.M.; Al-Abd, A.M.; El-Dine, R.S.; El-Halawany, A.M., P-glycoprotein inhibitors of natural origin as potential tumor chemo-sensitizers: A review. Journal of advanced research, 2015, 6, (1), 45-62.

[88] Lopez, D.; Martinez-Luis, S., Marine natural products with P-glycoprotein inhibitor properties. Marine drugs, 2014, 12, (1), 525-546.

[89] Michalak, K.; Wesolowska, O., Polyphenols counteract tumor cell chemoresistance conferred by multidrug resistance proteins. Anti-cancer agents in medicinal chemistry, 2012, 12, (8), 880-890.

[90] Farabegoli, F.; Papi, A.; Bartolini, G.; Ostan, R.; Orlandi, M., (-)-Epigallocatechin-3gallate downregulates Pg-P and BCRP in a tamoxifen resistant MCF-7 cell line. Phytomedicine : international journal of phytotherapy and phytopharmacology, 2010, 17, (5), 356-362.

[91] Li, Y.; Zhang, T.; Jiang, Y.; Lee, H.F.; Schwartz, S.J.; Sun, D., (-)-Epigallocatechin-3gallate inhibits Hsp90 function by impairing Hsp90 association with cochaperones in pancreatic cancer cell line Mia Paca-2. Molecular pharmaceutics, 2009, 6, (4), 1152-1159.

[92] Wesolowska, O.; Wisniewski, J.; Sroda, K.; Krawczenko, A.; Bielawska-Pohl, A.; Paprocka, M.; Dus, D.; Michalak, K., 8-Prenylnaringenin is an inhibitor of multidrug resistanceassociated transporters, P-glycoprotein and MRP1. European journal of pharmacology, 2010, 644, (1-3), 32-40.

[93] Milligan, S.R.; Kalita, J.C.; Heyerick, A.; Rong, H.; De Cooman, L.; De Keukeleire, D., Identification of a potent phytoestrogen in hops (Humulus lupulus L.) and beer. The Journal of clinical endocrinology and metabolism, 1999, 84, (6), 2249-2252.

[94] Sun, L.; Chen, W.; Qu, L.; Wu, J.; Si, J., Icaritin reverses multidrug resistance of HepG2/ADR human hepatoma cells via downregulation of MDR1 and Pglycoprotein expression. Molecular medicine reports, 2013, 8, (6), 1883-1887.

[95] Wu, J.; Du, J.; Fu, X.; Liu, B.; Cao, H.; Li, T.; Su, T.; Xu, J.; Tse, A.K.; Yu, Z.L., Iciartin, a novel FASN inhibitor, exerts anti-melanoma activities through IGF-1R/STAT3 signaling. Oncotarget, 2016, 7, (32), 51251-51269.

[96] Li, C.; Kim, M.; Choi, H.; Choi, J., Effects of baicalein on the pharmacokinetics of tamoxifen and its main metabolite, 4-hydroxytamoxifen, in rats: possible role of cytochrome P450 3A4 and P-glycoprotein inhibition by baicalein. Archives of pharmacal research, 2011, 34, (11), 1965-1972.

[97] Jelić, D.; Lower-Nedza, A.D.; Brantner, A.H.; Blažeković, B.; Bian, B.; Yang, J.; Brajša, K.; Vladimir-Knežević, S., Baicalin and Baicalein Inhibit Src Tyrosine Kinase and Production of IL-6. Journal of Chemistry, 2016, vol. 2016, (ID 2510621), 6 pages.

[98] Zhang, S.; Morris, M.E., Effect of the flavonoids biochanin A and silymarin on the Pglycoprotein-mediated transport of digoxin and vinblastine in human intestinal Caco-2 cells. Pharmaceutical research, 2003, 20, (8), 1184-1191. 
[99] Zhang, S.; Morris, M.E., Effects of the flavonoids biochanin A, morin, phloretin, and silymarin on P-glycoprotein-mediated transport. The Journal of pharmacology and experimental therapeutics, 2003, 304, (3), 1258-1267.

[100] Li, D.; Hu, J.; Wang, T.; Zhang, X.; Liu, L.; Wang, H.; Wu, Y.; Xu, D.; Wen, F., Silymarin attenuates cigarette smoke extract-induced inflammation via simultaneous inhibition of autophagy and ERK/p38 MAPK pathway in human bronchial epithelial cells. Scientific reports, 2016, 6, 37751.

[101] Borska, S.; Chmielewska, M.; Wysocka, T.; Drag-Zalesinska, M.; Zabel, M.; Dziegiel, P., In vitro effect of quercetin on human gastric carcinoma: targeting cancer cells death and MDR. Food and chemical toxicology : an international journal published for the British Industrial Biological Research Association, 2012, 50, (9), 3375-3383.

[102] Sergent, T.; Dupont, I.; Van der Heiden, E.; Scippo, M.L.; Pussemier, L.; Larondelle, Y.; Schneider, Y.J., CYP1A1 and CYP3A4 modulation by dietary flavonoids in human intestinal Caco-2 cells. Toxicology letters, 2009, 191, (2-3), 216-222.

[103] Choi, J.S.; Piao, Y.J.; Kang, K.W., Effects of quercetin on the bioavailability of doxorubicin in rats: role of CYP3A4 and P-gp inhibition by quercetin. Archives of pharmacal research, 2011, 34, (4), 607-613.

[104] Cheong, E.; Ivory, K.; Doleman, J.; Parker, M.L.; Rhodes, M.; Johnson, I.T., Synthetic and naturally occurring COX-2 inhibitors suppress proliferation in a human oesophageal adenocarcinoma cell line (OE33) by inducing apoptosis and cell cycle arrest. Carcinogenesis, 2004, 25, (10), 1945-1952.

[105] Choi, S.J.; Shin, S.C.; Choi, J.S., Effects of myricetin on the bioavailability of doxorubicin for oral drug delivery in rats: possible role of CYP3A4 and P-glycoprotein inhibition by myricetin. Archives of pharmacal research, 2011, 34, (2), 309-315.

[106] Kumamoto, T.; Fujii, M.; Hou, D.X., Akt is a direct target for myricetin to inhibit cell transformation. Molecular and cellular biochemistry, 2009, 332, (1-2), 33-41.

[107] Lee, E.; Enomoto, R.; Koshiba, C.; Hirano, H., Inhibition of P-glycoprotein by wogonin is involved with the potentiation of etoposide-induced apoptosis in cancer cells. Annals of the New York Academy of Sciences, 2009, 1171, 132-136.

[108] Polier, G.; Ding, J.; Konkimalla, B.V.; Eick, D.; Ribeiro, N.; Kohler, R.; Giaisi, M.; Efferth, T.; Desaubry, L.; Krammer, P.H.; Li-Weber, M., Wogonin and related natural flavones are inhibitors of CDK9 that induce apoptosis in cancer cells by transcriptional suppression of Mcl-1. Cell death \& disease, 2011, 2, e182.

[109] Al-Abd, A.M.; Mahmoud, A.M.; El-Sherbiny, G.A.; El-Moselhy, M.A.; Nofal, S.M.; ElLatif, H.A.; El-Eraky, W.I.; El-Shemy, H.A., Resveratrol enhances the cytotoxic profile of docetaxel and doxorubicin in solid tumour cell lines in vitro. Cell proliferation, 2011, 44, (6), 591-601.

[110] Zykova, T.A.; Zhu, F.; Zhai, X.; Ma, W.Y.; Ermakova, S.P.; Lee, K.W.; Bode, A.M.; Dong, Z., Resveratrol directly targets COX-2 to inhibit carcinogenesis. Molecular carcinogenesis, 2008, 47, (10), 797-805.

[111] Nabekura, T.; Hiroi, T.; Kawasaki, T.; Uwai, Y., Effects of natural nuclear factor-kappa $\mathrm{B}$ inhibitors on anticancer drug efflux transporter human P-glycoprotein. Biomedicine \& pharmacotherapy = Biomedecine \& pharmacotherapie, 2015, 70, 140-145.

[112] Chen, C.; Wu, C.; Lu, X.; Yan, Z.; Gao, J.; Zhao, H.; Li, S., Coniferyl Ferulate, a Strong Inhibitor of Glutathione S-Transferase Isolated from Radix Angelicae sinensis, Reverses Multidrug Resistance and Downregulates P-Glycoprotein. Evidence-based complementary and alternative medicine : eCAM, 2013, 2013, 639083.

[113] Novakovic, M.; Pesic, M.; Trifunovic, S.; Vuckovic, I.; Todorovic, N.; Podolski-Renic, A.; Dinic, J.; Stojkovic, S.; Tesevic, V.; Vajs, V.; Milosavljevic, S., Diarylheptanoids from the 
bark of black alder inhibit the growth of sensitive and multi-drug resistant non-small cell lung carcinoma cells. Phytochemistry, 2014, 97, 46-54.

[114] Han, J.M.; Lee, W.S.; Kim, J.R.; Son, J.; Kwon, O.H.; Lee, H.J.; Lee, J.J.; Jeong, T.S., Effect of 5-O-Methylhirsutanonol on nuclear factor-kappaB-dependent production of NO and expression of iNOS in lipopolysaccharide-induced RAW264.7 cells. Journal of agricultural and food chemistry, 2008, 56, (1), 92-98.

[115] Anand, P.; Thomas, S.G.; Kunnumakkara, A.B.; Sundaram, C.; Harikumar, K.B.; Sung, B.; Tharakan, S.T.; Misra, K.; Priyadarsini, I.K.; Rajasekharan, K.N.; Aggarwal, B.B., Biological activities of curcumin and its analogues (Congeners) made by man and Mother Nature. Biochemical pharmacology, 2008, 76, (11), 1590-1611.

[116] Oliveira, A.S.; Sousa, E.; Vasconcelos, M.H.; Pinto, M., Curcumin: A Natural Lead for Potential New Drug Candidates. Current medicinal chemistry, 2015, 22, (36), 4196-4232.

[117] Anuchapreeda, S.; Leechanachai, P.; Smith, M.M.; Ambudkar, S.V.; Limtrakul, P.N., Modulation of P-glycoprotein expression and function by curcumin in multidrug-resistant human KB cells. Biochemical pharmacology, 2002, 64, (4), 573-582.

[118] Tang, X.Q.; Bi, H.; Feng, J.Q.; Cao, J.G., Effect of curcumin on multidrug resistance in resistant human gastric carcinoma cell line SGC7901/VCR. Acta pharmacologica Sinica, 2005, 26, (8), 1009-1016.

[119] Lopes-Rodrigues, V.; Sousa, E.; Vasconcelos, M.H., Curcumin as a Modulator of PGlycoprotein in Cancer: Challenges and Perspectives. Pharmaceuticals (Basel), 2016, 9, (4).

[120] Limtrakul, P.; Anuchapreeda, S.; Buddhasukh, D., Modulation of human multidrugresistance MDR-1 gene by natural curcuminoids. BMC cancer, 2004, 4, 13.

[121] Lu, W.D.; Qin, Y.; Yang, C.; Li, L.; Fu, Z.X., Effect of curcumin on human colon cancer multidrug resistance in vitro and in vivo. Clinics, 2013, 68, (5), 694-701.

[122] Choi, B.H.; Kim, C.G.; Lim, Y.; Shin, S.Y.; Lee, Y.H., Curcumin down-regulates the multidrug-resistance mdr1b gene by inhibiting the PI3K/Akt/NF kappa B pathway. Cancer letters, 2008, 259, (1), 111-118.

[123] Andjelkovic, T.; Pesic, M.; Bankovic, J.; Tanic, N.; Markovic, I.D.; Ruzdijic, S., Synergistic effects of the purine analog sulfinosine and curcumin on the multidrug resistant human non-small cell lung carcinoma cell line (NCI-H460/R). Cancer biology \& therapy, 2008, 7, (7), 1024-1032.

[124] Lin, J.K., Molecular targets of curcumin. Advances in experimental medicine and biology, 2007, 595, 227-243.

[125] Kasi, P.D.; Tamilselvam, R.; Skalicka-Wozniak, K.; Nabavi, S.F.; Daglia, M.; Bishayee, A.; Pazoki-Toroudi, H.; Nabavi, S.M., Molecular targets of curcumin for cancer therapy: an updated review. Tumour biology : the journal of the International Society for Oncodevelopmental Biology and Medicine, 2016, 37, (10), 13017-13028.

[126] Kimura, S.; Ito, C.; Jyoko, N.; Segawa, H.; Kuroda, J.; Okada, M.; Adachi, S.; Nakahata, T.; Yuasa, T.; Filho, V.C.; Furukawa, H.; Maekawa, T., Inhibition of leukemic cell growth by a novel anti-cancer drug (GUT-70) from calophyllum brasiliense that acts by induction of apoptosis. International journal of cancer. Journal international du cancer, 2005, 113, (1), 158165.

[127] Jin, L.; Tabe, Y.; Kimura, S.; Zhou, Y.; Kuroda, J.; Asou, H.; Inaba, T.; Konopleva, M.; Andreeff, M.; Miida, T., Antiproliferative and proapoptotic activity of GUT-70 mediated through potent inhibition of Hsp90 in mantle cell lymphoma. British journal of cancer, 2011, 104, (1), 91-100.

[128] Hanafi-Bojd, M.Y.; Iranshahi, M.; Mosaffa, F.; Tehrani, S.O.; Kalalinia, F.; Behravan, J., Farnesiferol A from Ferula persica and galbanic acid from Ferula szowitsiana inhibit Pglycoprotein-mediated rhodamine efflux in breast cancer cell lines. Planta medica, 2011, 77, (14), 1590-1593. 
[129] Oh, B.S.; Shin, E.A.; Jung, J.H.; Jung, D.B.; Kim, B.; Shim, B.S.; Yazdi, M.C.; Iranshahi, M.; Kim, S.H., Apoptotic Effect of Galbanic Acid via Activation of Caspases and Inhibition of Mcl-1 in H460 Non-Small Lung Carcinoma Cells. Phytotherapy research : PTR, 2015, 29, (6), 844-849.

[130] Shahverdi, A.R.; Saadat, F.; Khorramizadeh, M.R.; Iranshahi, M.; Khoshayand, M.R., Two matrix metalloproteinases inhibitors from Ferula persica var. persica. Phytomedicine : international journal of phytotherapy and phytopharmacology, 2006, 13, (9-10), 712-717.

[131] Ohnishi, A.; Matsuo, H.; Yamada, S.; Takanaga, H.; Morimoto, S.; Shoyama, Y.; Ohtani, H.; Sawada, Y., Effect of furanocoumarin derivatives in grapefruit juice on the uptake of vinblastine by Caco-2 cells and on the activity of cytochrome P450 3A4. British journal of pharmacology, 2000, 130, (6), 1369-1377.

[132] Ge, Z.; Qu, X.; Yu, H.; Zhang, H.; Wang, Z.; Zhang, Z., Antitumor and apoptotic effects of bergaptol are mediated via mitochondrial death pathway and cell cycle arrest in human breast carcinoma cells. Bangladesh J Pharmacol, 2016, (11), 489-494

[133] Firestone, G.L.; Sundar, S.N., Anticancer activities of artemisinin and its bioactive derivatives. Expert reviews in molecular medicine, 2009, 11, e32.

[134] Mukanganyama, S.; Widersten, M.; Naik, Y.S.; Mannervik, B.; Hasler, J.A., Inhibition of glutathione S-transferases by antimalarial drugs possible implications for circumventing anticancer drug resistance. International journal of cancer. Journal international du cancer, 2002, 97, (5), 700-705.

[135] Steglich, B.; Mahringer, A.; Li, Y.; Posner, G.H.; Fricker, G.; Efferth, T., Inhibition of Pglycoprotein by two artemisinin derivatives. Nat Prod Bioprospect, 2012, 2, (2), 59-64.

[136] Aljancic, I.S.; Pesic, M.; Milosavljevic, S.M.; Todorovic, N.M.; Jadranin, M.; Milosavljevic, G.; Povrenovic, D.; Bankovic, J.; Tanic, N.; Markovic, I.D.; Ruzdijic, S.; Vajs, V.E.; Tesevic, V.V., Isolation and biological evaluation of jatrophane diterpenoids from Euphorbia dendroides. Journal of natural products, 2011, 74, (7), 1613-1620.

[137] Pesic, M.; Bankovic, J.; Aljancic, I.S.; Todorovic, N.M.; Jadranin, M.; Vajs, V.E.; Tesevic, V.V.; Vuckovic, I.; Momcilovic, M.; Markovic, I.D.; Tanic, N.; Ruzdijic, S., New anticancer characteristics of jatrophane diterpenes from Euphorbia dendroides. Food and chemical toxicology : an international journal published for the British Industrial Biological Research Association, 2011, 49, (12), 3165-3173.

[138] Sun, W.; Lv, C.; Zhu, T.; Yang, X.; Wei, S.; Sun, J.; Hong, K.; Zhu, W.; Huang, C., Ophiobolin-O reverses adriamycin resistance via cell cycle arrest and apoptosis sensitization in adriamycin-resistant human breast carcinoma (MCF-7/ADR) cells. Marine drugs, 2013, 11, (11), 4570-4584.

[139] Yang, T.; Lu, Z.; Meng, L.; Wei, S.; Hong, K.; Zhu, W.; Huang, C., The novel agent ophiobolin $\mathrm{O}$ induces apoptosis and cell cycle arrest of MCF-7 cells through activation of MAPK signaling pathways. Bioorganic \& medicinal chemistry letters, 2012, 22, (1), 579-585.

[140] Lv, C.; Qin, W.; Zhu, T.; Wei, S.; Hong, K.; Zhu, W.; Chen, R.; Huang, C., Ophiobolin O isolated from Aspergillus ustus induces G1 arrest of MCF-7 cells through interaction with AKT/GSK3beta/cyclin D1 signaling. Marine drugs, 2015, 13, (1), 431-443.

[141] Li, Y.; Fan, L.; Sun, Y.; Miao, X.; Zhang, F.; Meng, J.; Han, J.; Zhang, D.; Zhang, R.; Yue, Z.; Mei, Q., Paris saponin VII from trillium tschonoskii reverses multidrug resistance of adriamycin-resistant MCF-7/ADR cells via P-glycoprotein inhibition and apoptosis augmentation. Journal of ethnopharmacology, 2014, 154, (3), 728-734.

[142] Kim, S.W.; Kwon, H.Y.; Chi, D.W.; Shim, J.H.; Park, J.D.; Lee, Y.H.; Pyo, S.; Rhee, D.K., Reversal of P-glycoprotein-mediated multidrug resistance by ginsenoside $\operatorname{Rg}(3)$. Biochemical pharmacology, 2003, 65, (1), 75-82. 
[143] Kim, S.M.; Lee, S.Y.; Yuk, D.Y.; Moon, D.C.; Choi, S.S.; Kim, Y.; Han, S.B.; Oh, K.W.; Hong, J.T., Inhibition of NF-kappaB by ginsenoside $\mathrm{Rg} 3$ enhances the susceptibility of colon cancer cells to docetaxel. Archives of pharmacal research, 2009, 32, (5), 755-765.

[144] Junmin, S.; Hongxiang, L.; Zhen, L.; Chao, Y.; Chaojie, W., Ginsenoside Rg3 inhibits colon cancer cell migration by suppressing nuclear factor kappa B activity. Journal of traditional Chinese medicine = Chung $i$ tsa chih ying wen pan, 2015, 35, (4), 440-444.

[145] Xu, T.; Jin, Z.; Yuan, Y.; Wei, H.; Xu, X.; He, S.; Chen, S.; Hou, W.; Guo, Q.; Hua, B., Ginsenoside Rg3 Serves as an Adjuvant Chemotherapeutic Agent and VEGF Inhibitor in the Treatment of Non-Small Cell Lung Cancer: A Meta-Analysis and Systematic Review. Evidencebased complementary and alternative medicine : eCAM, 2016, 2016, 7826753.

[146] Kim, D.G.; Jung, K.H.; Lee, D.G.; Yoon, J.H.; Choi, K.S.; Kwon, S.W.; Shen, H.M.; Morgan, M.J.; Hong, S.S.; Kim, Y.S., 20(S)-Ginsenoside Rg3 is a novel inhibitor of autophagy and sensitizes hepatocellular carcinoma to doxorubicin. Oncotarget, 2014, 5, (12), 4438-4451.

[147] Nguyen, V.T.; Darbour, N.; Bayet, C.; Doreau, A.; Raad, I.; Phung, B.H.; Dumontet, C.; Di Pietro, A.; Dijoux-Franca, M.G.; Guilet, D., Selective modulation of P-glycoprotein activity by steroidal saponines from Paris polyphylla. Fitoterapia, 2009, 80, (1), 39-42.

[148] Chen, C.R.; Zhang, J.; Wu, K.W.; Liu, P.Y.; Wang, S.J.; Chen, D.Y.; Ji, Z.N., Gracillin induces apoptosis in HL60 human leukemic cell line via oxidative stress and cell cycle arrest of G1. Die Pharmazie, 2015, 70, (3), 199-204.

[149] Wu, L.; Li, Q.; Liu, Y., Polyphyllin D induces apoptosis in K562/A02 cells through G2/M phase arrest. The Journal of pharmacy and pharmacology, 2014, 66, (5), 713-721.

[150] Yu, Q.; Li, Q.; Lu, P.; Chen, Q., Polyphyllin D induces apoptosis in U87 human glioma cells through the c-Jun NH2-terminal kinase pathway. Journal of medicinal food, 2014, 17, (9), 1036-1042.

[151] Lei, Y.; Tan, J.; Wink, M.; Ma, Y.; Li, N.; Su, G., An isoquinoline alkaloid from the Chinese herbal plant Corydalis yanhusuo W.T. Wang inhibits P-glycoprotein and multidrug resistance-associate protein 1. Food chemistry, 2013, 136, (3-4), 1117-1121.

[152] Kang, H.; Jang, S.W.; Pak, J.H.; Shim, S., Glaucine inhibits breast cancer cell migration and invasion by inhibiting MMP-9 gene expression through the suppression of NF-kappaB activation. Molecular and cellular biochemistry, 2015, 403, (1-2), 85-94.

[153] Shiraishi, N.; Akiyama, S.; Nakagawa, M.; Kobayashi, M.; Kuwano, M., Effect of bisbenzylisoquinoline (biscoclaurine) alkaloids on multidrug resistance in KB human cancer cells. Cancer research, 1987, 47, (9), 2413-2416.

[154] Kato, T.; Suzumura, Y., Potentiation of antitumor activity of vincristine by the biscoclaurine alkaloid cepharanthine. Journal of the National Cancer Institute, 1987, 79, (3), 527-532.

[155] Nagaoka, S.; Kawasaki, S.; Karino, Y.; Sasaki, K.; Nakanishi, T., Modification of cellular efflux and cytotoxicity of adriamycin by biscoclaulin alkaloid in vitro. European journal of cancer \& clinical oncology, 1987, 23, (9), 1297-1302.

[156] Ikeda, R.; Che, X.F.; Yamaguchi, T.; Ushiyama, M.; Zheng, C.L.; Okumura, H.; Takeda, Y.; Shibayama, Y.; Nakamura, K.; Jeung, H.C.; Furukawa, T.; Sumizawa, T.; Haraguchi, M.; Akiyama, S.; Yamada, K., Cepharanthine potently enhances the sensitivity of anticancer agents in K562 cells. Cancer science, 2005, 96, (6), 372-376.

[157] Huang, C.Z.; Wang, Y.F.; Zhang, Y.; Peng, Y.M.; Liu, Y.X.; Ma, F.; Jiang, J.H.; Wang, Q.D., Cepharanthine hydrochloride reverses Pglycoprotein-mediated multidrug resistance in human ovarian carcinoma A2780/Taxol cells by inhibiting the PI3K/Akt signaling pathway. Oncology reports, 2017, 38, (4), 2558-2564.

[158] Hua, P.; Sun, M.; Zhang, G.; Zhang, Y.; Tian, X.; Li, X.; Cui, R.; Zhang, X., Cepharanthine induces apoptosis through reactive oxygen species and mitochondrial dysfunction 
in human non-small-cell lung cancer cells. Biochemical and biophysical research communications, 2015, 460, (2), 136-142.

[159] Chen, Z.; Huang, C.; Yang, Y.L.; Ding, Y.; Ou-Yang, H.Q.; Zhang, Y.Y.; Xu, M., Inhibition of the STAT3 signaling pathway is involved in the antitumor activity of cepharanthine in SaOS2 cells. Acta pharmacologica Sinica, 2012, 33, (1), 101-108.

[160] Haginaka, J.; Kitabatake, T.; Hirose, I.; Matsunaga, H.; Moaddel, R., Interaction of cepharanthine with immobilized heat shock protein 90alpha (Hsp90alpha) and screening of Hsp90alpha inhibitors. Analytical biochemistry, 2013, 434, (1), 202-206.

[161] Choi, S.U.; Park, S.H.; Kim, K.H.; Choi, E.J.; Kim, S.; Park, W.K.; Zhang, Y.H.; Kim, H.S.; Jung, N.P.; Lee, C.O., The bisbenzylisoquinoline alkaloids, tetrandine and fangchinoline, enhance the cytotoxicity of multidrug resistance-related drugs via modulation of P-glycoprotein. Anti-cancer drugs, 1998, 9, (3), 255-261.

[162] Sun, Y.F.; Wink, M., Tetrandrine and fangchinoline, bisbenzylisoquinoline alkaloids from Stephania tetrandra can reverse multidrug resistance by inhibiting P-glycoprotein activity in multidrug resistant human cancer cells. Phytomedicine : international journal of phytotherapy and phytopharmacology, 2014, 21, (8-9), 1110-1119.

[163] Cho, H.S.; Chang, S.H.; Chung, Y.S.; Shin, J.Y.; Park, S.J.; Lee, E.S.; Hwang, S.K.; Kwon, J.T.; Tehrani, A.M.; Woo, M.; Noh, M.S.; Hanifah, H.; Jin, H.; Xu, C.X.; Cho, M.H., Synergistic effect of ERK inhibition on tetrandrine-induced apoptosis in A549 human lung carcinoma cells. Journal of veterinary science, 2009, 10, (1), 23-28.

[164] Tian, F.; Ding, D.; Li, D., Fangchinoline targets PI3K and suppresses PI3K/AKT signaling pathway in SGC7901 cells. International journal of oncology, 2015, 46, (6), 23552363.

[165] Xing, Z.B.; Yao, L.; Zhang, G.Q.; Zhang, X.Y.; Zhang, Y.X.; Pang, D., Fangchinoline inhibits breast adenocarcinoma proliferation by inducing apoptosis. Chemical \& pharmaceutical bulletin, 2011, 59, (12), 1476-1480.

[166] Guo, B.; Su, J.; Zhang, T.; Wang, K.; Li, X., Fangchinoline as a kinase inhibitor targets FAK and suppresses FAK-mediated signaling pathway in A549. Journal of drug targeting, 2015, 23, (3), 266-274.

[167] Arora, A.; Seth, K.; Kalra, N.; Shukla, Y., Modulation of P-glycoprotein-mediated multidrug resistance in K562 leukemic cells by indole-3-carbinol. Toxicology and applied pharmacology, 2005, 202, (3), 237-243.

[168] Chinni, S.R.; Li, Y.; Upadhyay, S.; Koppolu, P.K.; Sarkar, F.H., Indole-3-carbinol (I3C) induced cell growth inhibition, G1 cell cycle arrest and apoptosis in prostate cancer cells. Oncogene, 2001, 20, (23), 2927-2936.

[169] Wang, X.; Deng, R.; Lu, Y.; Xu, Q.; Yan, M.; Ye, D.; Chen, W., Gambogic acid as a non-competitive inhibitor of ATP-binding cassette transporter B1 reverses the multidrug resistance of human epithelial cancers by promoting ATP-binding cassette transporter B1 protein degradation. Basic \& clinical pharmacology \& toxicology, 2013, 112, (1), 25-33.

[170] Davenport, J.; Manjarrez, J.R.; Peterson, L.; Krumm, B.; Blagg, B.S.; Matts, R.L., Gambogic acid, a natural product inhibitor of Hsp90. Journal of natural products, 2011, 74, (5), 1085-1092.

[171] Gu, H.; Rao, S.; Zhao, J.; Wang, J.; Mu, R.; Rong, J.; Tao, L.; Qi, Q.; You, Q.; Guo, Q., Gambogic acid reduced bcl-2 expression via p53 in human breast MCF-7 cancer cells. Journal of cancer research and clinical oncology, 2009, 135, (12), 1777-1782.

[172] Zhu, H.J.; Wang, J.S.; Markowitz, J.S.; Donovan, J.L.; Gibson, B.B.; Gefroh, H.A.; Devane, C.L., Characterization of P-glycoprotein inhibition by major cannabinoids from marijuana. The Journal of pharmacology and experimental therapeutics, 2006, 317, (2), 850857. 
[173] Feinshtein, V.; Erez, O.; Ben-Zvi, Z.; Erez, N.; Eshkoli, T.; Sheizaf, B.; Sheiner, E.; Huleihel, M.; Holcberg, G., Cannabidiol changes P-gp and BCRP expression in trophoblast cell lines. PeerJ, 2013, 1 , e153.

[174] Shrivastava, A.; Kuzontkoski, P.M.; Groopman, J.E.; Prasad, A., Cannabidiol induces programmed cell death in breast cancer cells by coordinating the cross-talk between apoptosis and autophagy. Molecular cancer therapeutics, 2011, 10, (7), 1161-1172.

[175] Dacevic, M.; Isakovic, A.; Podolski-Renic, A.; Isakovic, A.M.; Stankovic, T.; Milosevic, Z.; Rakic, L.; Ruzdijic, S.; Pesic, M., Purine nucleoside analog--sulfinosine modulates diverse mechanisms of cancer progression in multi-drug resistant cancer cell lines. PloS one, 2013, 8, (1), e54044.

[176] Pesic, M.; Podolski, A.; Rakic, L.; Ruzdijic, S., Purine analogs sensitize the multidrug resistant cell line (NCI-H460/R) to doxorubicin and stimulate the cell growth inhibitory effect of verapamil. Investigational new drugs, 2010, 28, (4), 482-492.

[177] Pesic, M.; Andjelkovic, T.; Bankovic, J.; Markovic, I.D.; Rakic, L.; Ruzdijic, S., Sulfinosine enhances doxorubicin efficacy through synergism and by reversing multidrug resistance in the human non-small cell lung carcinoma cell line (NCI-H460/R). Investigational new drugs, 2009, 27, (2), 99-110.

[178] Bankovic, J.; Andra, J.; Todorovic, N.; Podolski-Renic, A.; Milosevic, Z.; Miljkovic, D.; Krause, J.; Ruzdijic, S.; Tanic, N.; Pesic, M., The elimination of P-glycoprotein over-expressing cancer cells by antimicrobial cationic peptide NK-2: the unique way of multi-drug resistance modulation. Experimental cell research, 2013, 319, (7), 1013-1027.

[179] Lu, Y.; Chen, J.; Xiao, M.; Li, W.; Miller, D.D., An overview of tubulin inhibitors that interact with the colchicine binding site. Pharmaceutical research, 2012, 29, (11), 2943-2971.

[180] Cheung, C.H.; Wu, S.Y.; Lee, T.R.; Chang, C.Y.; Wu, J.S.; Hsieh, H.P.; Chang, J.Y., Cancer cells acquire mitotic drug resistance properties through beta I-tubulin mutations and alterations in the expression of beta-tubulin isotypes. PloS one, 2010, 5, (9), e12564.

[181] Kavallaris, M.; Verrills, N.M.; Hill, B.T., Anticancer therapy with novel tubulininteracting drugs. Drug resistance updates : reviews and commentaries in antimicrobial and anticancer chemotherapy, 2001, 4, (6), 392-401.

[182] Jordan, M.A.; Wilson, L., Microtubules as a target for anticancer drugs. Nat Rev Cancer, 2004, 4, (4), 253-265.

[183] Podolski-Renic, A.; Andelkovic, T.; Bankovic, J.; Tanic, N.; Ruzdijic, S.; Pesic, M., The role of paclitaxel in the development and treatment of multidrug resistant cancer cell lines. Biomedicine \& pharmacotherapy = Biomedecine \& pharmacotherapie, 2011, 65, (5), 345-353.

[184] Parker, A.L.; Teo, W.S.; McCarroll, J.A.; Kavallaris, M., An Emerging Role for Tubulin Isotypes in Modulating Cancer Biology and Chemotherapy Resistance. International journal of molecular sciences, 2017, 18, (7), 1434.

[185] Zhang, Q.; Zhai, S.; Li, L.; Li, X.; Zhou, H.; Liu, A.; Su, G.; Mu, Q.; Du, Y.; Yan, B., Anti-tumor selectivity of a novel tubulin and HSP90 dual-targeting inhibitor in non-small cell lung cancer models. Biochemical pharmacology, 2013, 86, (3), 351-360.

[186] Jackson, S.E., Hsp90: structure and function. Topics in current chemistry, 2013, 328, 155-240.

[187] Zhang, Q.; Zhai, S.; Li, L.; Li, X.; Jiang, C.; Zhang, C.; Yan, B., P-glycoprotein-evading anti-tumor activity of a novel tubulin and HSP90 dual inhibitor in a non-small-cell lung cancer model. Journal of pharmacological sciences, 2014, 126, (1), 66-76.

[188] Zhang, L.H.; Wu, L.; Raymon, H.K.; Chen, R.S.; Corral, L.; Shirley, M.A.; Narla, R.K.; Gamez, J.; Muller, G.W.; Stirling, D.I.; Bartlett, J.B.; Schafer, P.H.; Payvandi, F., The synthetic compound CC-5079 is a potent inhibitor of tubulin polymerization and tumor necrosis factoralpha production with antitumor activity. Cancer research, 2006, 66, (2), 951-959. 
[189] Hideshima, T.; Chauhan, D.; Podar, K.; Schlossman, R.L.; Richardson, P.; Anderson, K.C., Novel therapies targeting the myeloma cell and its bone marrow microenvironment. Seminars in Oncology, 2001, 28, (6), 607-612.

[190] Montserrat, E., Chronic lymphoproliferative disorders. Current opinion in oncology, 1997, 9, (1), 34-41.

[191] Jin, S.L.; Conti, M., Induction of the cyclic nucleotide phosphodiesterase PDE4B is essential for LPS-activated TNF-alpha responses. Proceedings of the National Academy of Sciences of the United States of America, 2002, 99, (11), 7628-7633.

[192] Sakamoto, M.; Takamura, M.; Ino, Y.; Miura, A.; Genda, T.; Hirohashi, S., Involvement of c-Src in carcinoma cell motility and metastasis. Japanese journal of cancer research : Gann, 2001, 92, (9), 941-946.

[193] Schlessinger, J., New roles for Src kinases in control of cell survival and angiogenesis. Cell, 2000, 100, (3), 293-296.

[194] Anbalagan, M.; Carrier, L.; Glodowski, S.; Hangauer, D.; Shan, B.; Rowan, B.G., KX-01, a novel Src kinase inhibitor directed toward the peptide substrate site, synergizes with tamoxifen in estrogen receptor alpha positive breast cancer. Breast cancer research and treatment, 2012 , 132, (2), 391-409.

[195] Fallah-Tafti, A.; Foroumadi, A.; Tiwari, R.; Shirazi, A.N.; Hangauer, D.G.; Bu, Y.; Akbarzadeh, T.; Parang, K.; Shafiee, A., Thiazolyl N-benzyl-substituted acetamide derivatives: synthesis, Src kinase inhibitory and anticancer activities. European journal of medicinal chemistry, 2011, 46, (10), 4853-4858.

[196] ClinicalTrials.gov Evaluation of KX2-391 in Elderly Subjects With Acute Myeloid Leukemia

https://clinicaltrials.gov/ct2/show/NCT01397799?term=NCT01397799\&rank=1

[197] ClinicalTrials.gov A Safety and Efficacy Study of KX2-391 in Patients With BoneMetastatic, Castration-Resistant Prostate Cancer Who Have Not Received Prior Chemotherapy. https://clinicaltrials.gov/ct2/show/NCT01074138?term=NCT01074138\&rank=1

[198] Anbalagan, M.; Ali, A.; Jones, R.K.; Marsden, C.G.; Sheng, M.; Carrier, L.; Bu, Y.; Hangauer, D.; Rowan, B.G., Peptidomimetic Src/pretubulin inhibitor KX-01 alone and in combination with paclitaxel suppresses growth, metastasis in human ER/PR/HER2-negative tumor xenografts. Molecular cancer therapeutics, 2012, 11, (9), 1936-1947.

[199] Palma, G.; Frasci, G.; Chirico, A.; Esposito, E.; Siani, C.; Saturnino, C.; Arra, C.; Ciliberto, G.; Giordano, A.; D'Aiuto, M., Triple negative breast cancer: looking for the missing link between biology and treatments. Oncotarget, 2015, 6, (29), 26560-26574.

[200] Pommier, Y., Drugging topoisomerases: lessons and challenges. ACS chemical biology, 2013, 8, (1), 82-95.

[201] Nelson, W.G.; Liu, L.F.; Coffey, D.S., Newly replicated DNA is associated with DNA topoisomerase II in cultured rat prostatic adenocarcinoma cells. Nature, 1986, 322, (6075), 187 189.

[202] Gasser, S.M.; Laroche, T.; Falquet, J.; Boy de la Tour, E.; Laemmli, U.K., Metaphase chromosome structure. Involvement of topoisomerase II. Journal of molecular biology, 1986, $188,(4), 613-629$.

[203] Zhang, H.; Wang, J.C.; Liu, L.F., Involvement of DNA topoisomerase I in transcription of human ribosomal RNA genes. Proceedings of the National Academy of Sciences of the United States of America, 1988, 85, (4), 1060-1064.

[204] Alagoz, M.; Gilbert, D.C.; El-Khamisy, S.; Chalmers, A.J., DNA repair and resistance to topoisomerase I inhibitors: mechanisms, biomarkers and therapeutic targets. Current medicinal chemistry, 2012, 19, (23), 3874-3885.

[205] Hamelin, C.; Cousineau, L.; Dion, M.; Yelle, J., Increased DNA topoisomerase I activity in aging human cell chromatin. Bioscience reports, 1984, 4, (10), 861-868. 
[206] Nitiss, J.L., DNA topoisomerase II and its growing repertoire of biological functions. Nature reviews. Cancer, 2009, 9, (5), 327-337.

[207] Liu, L.F.; Rowe, T.C.; Yang, L.; Tewey, K.M.; Chen, G.L., Cleavage of DNA by mammalian DNA topoisomerase II. The Journal of biological chemistry, 1983, 258, (24), 15365 15370.

[208] Lin, C.P.; Ban, Y.; Lyu, Y.L.; Liu, L.F., Proteasome-dependent processing of topoisomerase I-DNA adducts into DNA double strand breaks at arrested replication forks. The Journal of biological chemistry, 2009, 284, (41), 28084-28092.

[209] Pizzolato, J.F.; Saltz, L.B., The camptothecins. Lancet (London, England), 2003, 361, (9376), 2235-2242.

[210] Pommier, Y., Topoisomerase I inhibitors: camptothecins and beyond. Nature Reviews Cancer, 2006, 6, (10), 789-802.

[211] Bailly, C., Contemporary challenges in the design of topoisomerase II inhibitors for cancer chemotherapy. Chemical reviews, 2012, 112, (7), 3611-3640.

[212] Hande, K.R., Topoisomerase II inhibitors. Update on Cancer Therapeutics, 2008, 3, (1), 13-26.

[213] Pilati, P.; Nitti, D.; Mocellin, S., Cancer resistance to type II topoisomerase inhibitors. Current medicinal chemistry, 2012, 19, (23), 3900-3906.

[214] Pesic, M.; Markovic, J.Z.; Jankovic, D.; Kanazir, S.; Markovic, I.D.; Rakic, L.; Ruzdijic, S., Induced resistance in the human non small cell lung carcinoma (NCI-H460) cell line in vitro by anticancer drugs. Journal of chemotherapy, 2006, 18, (1), 66-73.

[215] Eder, J.P.; Chan, V.; Wong, J.; Wong, Y.W.; Ara, G.; Northey, D.; Rizvi, N.; Teicher, B.A., Sequence effect of irinotecan (CPT-11) and topoisomerase II inhibitors in vivo. Cancer chemotherapy and pharmacology, 1998, 42, (4), 327-335.

[216] Crump, M.; Lipton, J.; Hedley, D.; Sutton, D.; Shepherd, F.; Minden, M.; Stewart, K.; Beare, S.; Eisenhauer, E., Phase I trial of sequential topotecan followed by etoposide in adults with myeloid leukemia: a National Cancer Institute of Canada Clinical Trials Group Study. Leukemia, 1999, 13, 343.

[217] Perrin, D.; van Hille, B.; Barret, J.M.; Kruczynski, A.; Etievant, C.; Imbert, T.; Hill, B.T., F 11782, a novel epipodophylloid non-intercalating dual catalytic inhibitor of topoisomerases I and II with an original mechanism of action. Biochemical pharmacology, 2000, 59, (7), 807-819. [218] Kruczynski, A.; Etievant, C.; Perrin, D.; Imbert, T.; Colpaert, F.; Hill, B.T., Preclinical antitumour activity of F 11782, a novel dual catalytic inhibitor of topoisomerases. British journal of cancer, 2000, 83, (11), 1516-1524.

[219] Kruczynski, A.; Ricome, C.; Waud, W.R.; Hill, B.T., In vivo antitumor activity of F 11782, a non-intercalating dual catalytic inhibitor of topoisomerases I and II, against a panel of human tumor xenografts. Journal of experimental therapeutics \& oncology, 2002, 2, (4), 219227.

[220] Barret, J.-M.; Cadou, M.; Hill, B.T., Inhibition of nucleotide excision repair and sensitisation of cells to DNA cross-linking anticancer drugs by $\mathrm{F} 11782$, a novel fluorinated epipodophylloid. Biochemical pharmacology, 2002, 63, (2), 251-258.

[221] Kluza, J.; Mazinghien, R.; Irwin, H.; Hartley, J.A.; Bailly, C., Relationships between DNA strand breakage and apoptotic progression upon treatment of HL-60 leukemia cells with tafluposide or etoposide. Anti-cancer drugs, 2006, 17, (2), 155-164.

[222] M. Martínez-Viturro, C.; Domínguez, D. Synthesis of the Antitumoral Agent Batracylin and Related Isoindolo[1,2-b]quinazolin-12(10H)-ones, Tetrahedron Letters, 2007, 48, (6), 1023 1026.

[223] Monks, A.; Scudiero, D.; Skehan, P.; Shoemaker, R.; Paull, K.; Vistica, D.; Hose, C.; Langley, J.; Cronise, P.; Vaigro-Wolff, A.; et al., Feasibility of a high-flux anticancer drug 
screen using a diverse panel of cultured human tumor cell lines. Journal of the National Cancer Institute, 1991, 83, (11), 757-766.

[224] Rao, V.A.; Agama, K.; Holbeck, S.; Pommier, Y., Batracylin (NSC 320846), a dual inhibitor of DNA topoisomerases I and II induces histone gamma-H2AX as a biomarker of DNA damage. Cancer research, 2007, 67, (20), 9971-9979.

[225] Pourquier, P.; Pommier, Y. In Advances in Cancer Research; Academic Press, 2001; Vol. 80, pp 189-216.

[226] Mistry, P.; Stewart, A.J.; Dangerfield, W.; Baker, M.; Liddle, C.; Bootle, D.; Kofler, B.; Laurie, D.; Denny, W.A.; Baguley, B.; Charlton, P.A., In vitro and in vivo characterization of XR11576, a novel, orally active, dual inhibitor of topoisomerase I and II. Anti-cancer drugs, 2002, 13, (1), 15-28.

[227] Jobson, A.G.; Willmore, E.; Tilby, M.J.; Mistry, P.; Charlton, P.; Austin, C.A., Effect of phenazine compounds XR11576 and XR5944 on DNA topoisomerases. Cancer chemotherapy and pharmacology, 2009, 63, (5), 889-901.

[228] Di Nicolantonio, F.P., A.; Mills, L.; Knight, L. A.; Charlton, P. A.; Cree, I. A. , The effect of MDR1 on the ex vivo activity of XR5944 (MLN944) and XR11576 (MLN576), two novel DNA targeting agents. European journal of cancer, 38, S32.

[229] Yi, J.-M.; Zhang, X.-F.; Huan, X.-J.; Song, S.-S.; Wang, W.; Tian, Q.-T.; Sun, Y.-M.; Chen, Y.; Ding, J.; Wang, Y.-Q.; Yang, C.-H.; Miao, Z.-H., Dual targeting of microtubule and topoisomerase II by $\alpha$-carboline derivative $\mathrm{YCH} 337$ for tumor proliferation and growth inhibition. Oncotarget, 2015, 6, (11), 8960-8973.

[230] Cervinka, M.; Cerman, J.; Rudolf, E., Apoptosis in Hep2 cells treated with etoposide and colchicine. Cancer detection and prevention, 2004, 28, (3), 214-226.

[231] Podolski-Renic, A.; Bankovic, J.; Dinic, J.; Rios-Luci, C.; Fernandes, M.X.; Ortega, N.; Kovacevic-Grujicic, N.; Martin, V.S.; Padron, J.M.; Pesic, M., DTA0100, dual topoisomerase II and microtubule inhibitor, evades paclitaxel resistance in P-glycoprotein overexpressing cancer cells. European journal of pharmaceutical sciences : official journal of the European Federation for Pharmaceutical Sciences, 2017, 105, 159-168.

[232] Silveira-Dorta, G.; Sousa, I.J.; Rios-Luci, C.; Martin, V.S.; Fernandes, M.X.; Padron, J.M., Molecular docking studies of the interaction between propargylic enol ethers and human DNA topoisomerase IIalpha. Bioorganic \& medicinal chemistry letters, 2013, 23, (19), 53825384.

[233] Chang, J.Y.; Hsieh, H.P.; Pan, W.Y.; Liou, J.P.; Bey, S.J.; Chen, L.T.; Liu, J.F.; Song, J.S., Dual inhibition of topoisomerase I and tubulin polymerization by BPR0Y007, a novel cytotoxic agent. Biochemical pharmacology, 2003, 65, (12), 2009-2019.

[234] Kerru, N.; Singh, P.; Koorbanally, N.; Raj, R.; Kumar, V., Recent advances (2015-2016) in anticancer hybrids. European journal of medicinal chemistry, 2017, 142, 179-212.

[235] Musso, L.; Dallavalle, S.; Zunino, F., Perspectives in the development of hybrid bifunctional antitumour agents. Biochemical pharmacology, 2015, 96, (4), 297-305.

[236] Gu, X.; Ren, Z.; Tang, X.; Peng, H.; Ma, Y.; Lai, Y.; Peng, S.; Zhang, Y., Synthesis and biological evaluation of bifendate-chalcone hybrids as a new class of potential P-glycoprotein inhibitors. Bioorganic \& medicinal chemistry, 2012, 20, (8), 2540-2548.

[237] Palmeira, A.; Vasconcelos, M.H.; Paiva, A.; Fernandes, M.X.; Pinto, M.; Sousa, E., Dual inhibitors of P-glycoprotein and tumor cell growth: (re)discovering thioxanthones. Biochemical pharmacology, 2012, 83, (1), 57-68.

[238] Zhang, W.; Guo, J.; Li, S.; Ma, T.; Xu, D.; Han, C.; Liu, F.; Yu, W.; Kong, L., Discovery of monocarbonyl curcumin-BTP hybrids as STAT3 inhibitors for drug-sensitive and drugresistant breast cancer therapy. Scientific reports, 2017, 7, 46352. 
[239] Xu, S.; Pei, L.; Wang, C.; Zhang, Y.K.; Li, D.; Yao, H.; Wu, X.; Chen, Z.S.; Sun, Y.; Xu, J., Novel hybrids of natural oridonin-bearing nitrogen mustards as potential anticancer drug candidates. ACS medicinal chemistry letters, 2014, 5, (7), 797-802.

[240] Singh, P.; Paul, K., Studies of interactions between uracil-based hybrid molecules and Pglycoprotein--search for multidrug resistance modulators. Bioorganic \& medicinal chemistry, 2006, 14, (21), 7183-7186.

[241] Huang, X.; Huang, R.; Gou, S.; Wang, Z.; Liao, Z.; Wang, H., Platinum(IV) complexes conjugated with phenstatin analogue as inhibitors of microtubule polymerization and reverser of multidrug resistance. Bioorganic \& medicinal chemistry, 2017, 25, (17), 4686-4700.

[242] Novohradsky, V.; Zerzankova, L.; Stepankova, J.; Vrana, O.; Raveendran, R.; Gibson, D.; Kasparkova, J.; Brabec, V., Antitumor platinum(IV) derivatives of oxaliplatin with axial valproato ligands. Journal of inorganic biochemistry, 2014, 140, 72-79.

[243] Johnstone, T.C.; Suntharalingam, K.; Lippard, S.J., The Next Generation of Platinum Drugs: Targeted Pt(II) Agents, Nanoparticle Delivery, and Pt(IV) Prodrugs. Chemical reviews, 2016, 116, (5), 3436-3486.

[244] Cincinelli, R.; Musso, L.; Dallavalle, S.; Artali, R.; Tinelli, S.; Colangelo, D.; Zunino, F.; De Cesare, M.; Beretta, G.L.; Zaffaroni, N., Design, modeling, synthesis and biological activity evaluation of camptothecin-linked platinum anticancer agents. European journal of medicinal chemistry, 2013, 63, 387-400.

[245] Cincinelli, R.; Musso, L.; Artali, R.; Guglielmi, M.; Bianchino, E.; Cardile, F.; Colelli, F.; Pisano, C.; Dallavalle, S., Camptothecin-psammaplin A hybrids as topoisomerase I and HDAC dual-action inhibitors. European journal of medicinal chemistry, 2018, 143, 2005-2014. 